\begin{tabular}{|c|l|}
\hline Title & $\begin{array}{l}\text { Combustion Noise Reduction with High Thermal Efficiency by the Control of Multiple Fuel Injections in Premixed } \\
\text { Diesel Engines }\end{array}$ \\
\hline Author(s) & Shibata, Gen; Ogawa, Hideyuki; Okamoto, Y uki; A manuma, Y asumasa; Kobashi, Y oshimitsu \\
\hline Citation & $\begin{array}{l}\text { SAE International journal of engines, 10(3), 1128-1142 } \\
\text { https://doi.org/L0.4271/2017-01-0706 }\end{array}$ \\
\hline Issue Date & 2017-06 \\
\hline Doc URL & http://hdl.handle.net/2115/67727 \\
\hline Rights & O2017 SAE International \\
\hline Type & article (author version) \\
\hline File Information & SAE Paper 2017-01-0706 for Huscap.pdf \\
\hline
\end{tabular}

Instructions for use 


\title{
Combustion Noise Reduction with High Thermal Efficiency by the Control of Multiple Fuel Injections in Premixed Diesel Engines
}

\author{
Gen Shibata, Hideyuki Ogawa, Yuki Okamoto, Yasumasa Amanuma, and Yoshimitsu Kobashi
}

Hokkaido University

\begin{abstract}
Premixed diesel combustion is effective for high thermal efficiency and reductions of NOx and PM emissions, but a reduction of combustion noise is necessary for medium-high load engine operation. The control of the fuel injection has become more accurate because of the technical progress of the common rail fuel injection system, and the target heat release shape, calculated by computation, can be achieved by control of EGR, boosting, fuel injection timing, and injection quantity of multiple fuel injections.
\end{abstract}

In this paper, the reduction of premixed diesel combustion noise maintaining high thermal efficiency has been investigated by the control of injection timings and heating values of multiple fuel injections. There are two aspects of the combustion noise reduction by multiple fuel injections. One is the reduction of the maximum rate of pressure rise in each combustion cycle, and the other is noise reduction effects by the noise cancelling spike (NCS) combustion.

The research was conducted with both engine simulations and experiments. In combustion noise simulations, the heat release history of multiple injections was approximated by Wiebe functions and the simulated combustion noise was calculated from the fitted curve of the heat release and the coherence transfer function. The structural attenuation (SA) of the test engine was calculated from the power spectrum of the FFT analysis of the in-cylinder pressure wave data and the cross power spectrum of the sound pressure of the engine noise by the coherence method, then the combustion noise (CNL) can be calculated from the structural attenuation and cylinder pressure level (CPL) in the simulation, as shown in equation 4 . The simulation results were confirmed by the engine tests.

First, the combustion noise reduction by two stage fuel injection was investigated. The maximum rate of pressure rise changes depending on the combustion occurring separately in the compression and expansion strokes. One heat release was set at TDC and the second before or after the TDC. In the late two stage combustion as shown in Figure 12 (b), the combustion noise reduction was most effectively achieved when the heating value of $Q_{2 n d}$ is higher than that of $Q_{1 s t}$, however in the early two stage combustion in Figure 12 (a), the $Q_{1 s t}$ heat release occurs during the compression stroke and the combustion noise reduction by the early two stage NCS combustion is more effective than the combustion noise reduction by the late two stage NCS combustion.

Three stage combustion simulations were also investigated at $0.6 \mathrm{MPa}$ IMEP and $2000 \mathrm{rpm}$. The optimum heat release shape for low combustion noise and high indicated thermal efficiency was

Page 1 of 15 calculated and the role of each part of the heat release in the three stage combustion is discussed. The simulation predicted $87.1 \mathrm{dBA}$ of combustion noise and $50.3 \%$ of indicated thermal efficiency.

Finally, the effects of multiple fuel injections on the degree of constant volume and combustion noise are analyzed and discussed.

\section{Introduction}

Much research has been on the reduction of diesel engine combustion noise by engine tests. Kojima reported the relation between combustion noise and burning rates [1] and explained the characteristics of combustion noise generation [2, 3]. Sjoberg [4] and Johansson [5] reported the ringing intensity control and the relation between combustion noise and pressure history was reported by Scarpati [6] and Ghandi [7].

The maximum rate of pressure rise is a main cause of the combustion noise, and Shibata and Shibaike investigated other factors in the combustion noise generation [8]. There, eighteen engine tests were conducted at one maximum rate of pressure rise condition (1.0 $\mathrm{MPa} / \mathrm{CA}$ ), and it was statistically determined that the maximum rate of heat release $\left(R H R_{\max }\right)$ and the crank angle of $50 \%$ burn $(C A 50)$ are the second and third parameters in the combustion noise. The combustion noise reduction was achieved by EGR and boosting to control the $R H R_{\max }$ and CA50 maintaining the maximum pressure rise rate at $1.0 \mathrm{MPa} / \mathrm{CA}$. Okubo developed a combustion noise simulation method by coherence analysis [9]. This simulation technique was improved for the premixed diesel engine with the Wiebe function [10, 11], making the combustion noise prediction for multiple fuel injections possible.

Fuyuto reported the phenomenon that combustion noise generated in the second combustion could assist in reducing the combustion noise of the first fuel injection, termed "Noise Cancelling Spike Combustion (NCS combustion)" [12]. The NCS effects were investigated by engine tests and simulations, and an optimum heat release shape for low engine noise and high thermal efficiency was suggested [13]. Multiple fuel injection is effective to lower the combustion noise because of the reduction in the maximum rate of pressure rise in each separate combustion and NCS combustion effects.

In this paper, two topics are investigated. One is a further investigation of the combustion noise reduction by the dual fuel injections. Here heat release occurs at TDC and the effects of a heat release before TDC (compression stroke) or after the TDC (expansion stroke) on NCS effects were investigated 
The other topic is combustion noise reduction by three fuel injections near TDC. For the dual fuel injections, there is generally amplification of the frequency of the combustion noise and the NCS effect is small. The third fuel injection is effective in lowering of the combustion noise of the amplified frequency and the optimum heat release shape of the three stage combustion was investigated by simulations and engine tests. Finally, the effects of multiple fuel injections on the degree of constant volume and combustion noise are analyzed and discussed.

\section{Experimental}

\section{Engine Bench Set up}

A schematic outline of the research engine bench is shown in Figure 1. The engine employed in the experiments was a supercharged, single cylinder DI diesel research engine, with a high pressure common rail fuel injection system for injection pressures up to 180 MPa. The specifications of the diesel engine are given in Table 1. The fuel used in the experiments was the commercially available \#2 Japanese diesel fuel classified by JIS K2204 specifications (a cetane number of 54). The intake air was measured by an orifice flow meter and mixed with low pressure cooled EGR gas boosted by a supercharger, before being supplied to the engine. The intake manifold was equipped with an electric heater to maintain the intake air temperature at $25^{\circ} \mathrm{C}$. The engine was equipped with a pressure transducer (Kisler 6125A) and pressure data was transmitted to a PC as 45 cycles of crank angle resolved pressure data averaged over the 45 cycles. For all test conditions in this paper, the water and engine oil temperatures were maintained at $80^{\circ} \mathrm{C}$.

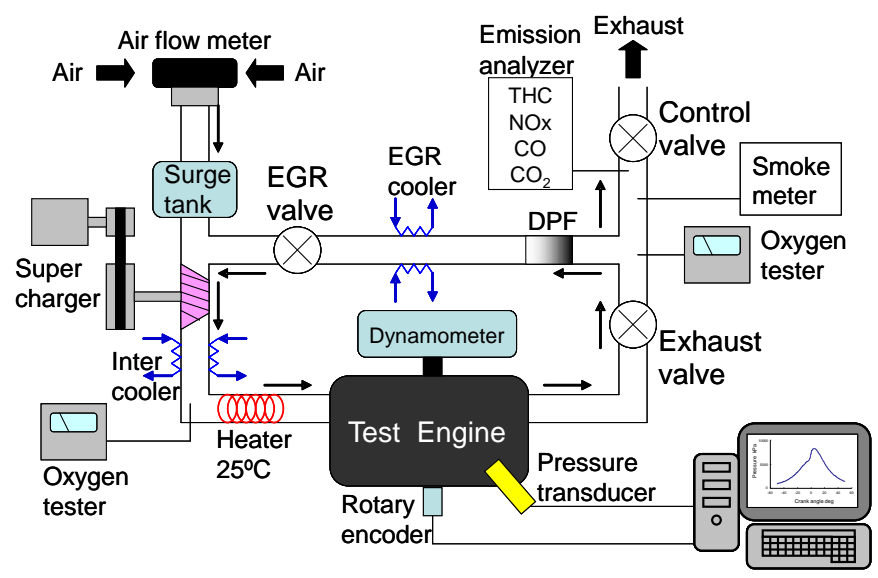

Figure 1. Outline of the engine test set-up

Table 1. Test engine specifications

\begin{tabular}{|l|c|}
\hline Number of cylinders & 1 \\
\hline Bore $\times$ Stroke & $\phi 85 \times 96.9 \mathrm{~mm}$ \\
\hline Displacement & $550 \mathrm{~cm}^{3}$ \\
\hline Compression ratio & $16.3: 1$ \\
\hline Fuel injection system & Common rail \\
\hline Nozzle hole & $\phi 0.125 \times 7$ \\
\hline Spray angle & $156^{\circ}$ \\
\hline Connecting rod/crank radius ratio & $\mathrm{L} / \mathrm{R}=3.1$ \\
\hline
\end{tabular}

Page 2 of 15

\section{Noise Measurements and Calculations}

\section{Measurements of the Engine Noise}

The engine and combustion noise were evaluated with the noise measurement arrangement shown schematically in Figure 2. The supercharger in the right side is surrounded by the acoustic absorption panels and materials, and microphones were set at two sampling positions at the cylinder head top height (one $1 \mathrm{~m}$ away from the front of the engine and the other $1 \mathrm{~m}$ away to the left of the engine) and engine noise was collected from the left side and front of engines, avoiding the sampling of the transmission noise in the rear side of the engine. The sampled noise was averaged and analyzed by an FFT sound analyzers (Onosokki LA-1410 and DS-3000) and a 1/3 octave band filter was used for the analysis of the frequency characteristics.

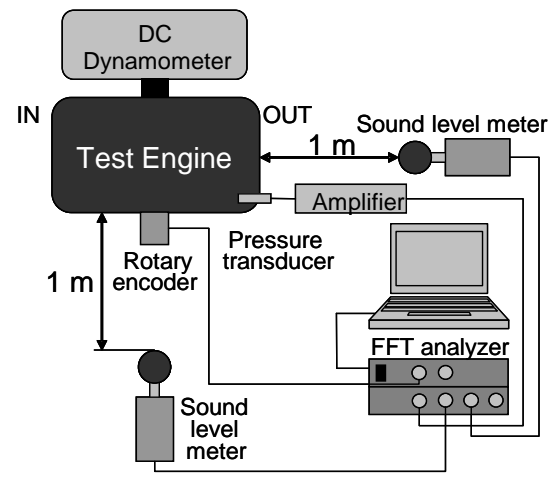

Figure 2. Engine noise measurement setup

\section{Calculations of Combustion Noise [9]}

The model used to analyze the engine noise is outlined in Figure 3. The engine noise value is comprised of the combustion noise level by the coherence method (CCNL) and the mechanical noise level (MNL) as shown in equation 1 below, assuming that the cylinder pressure and combustion noise levels are closely related. The transfer characteristic $\mathrm{H}$ was calculated from the power spectrum by the FFT analysis of the in-cylinder pressure waveform and the cross spectrum of the sound pressure of the engine noise level and pressure waveform. With this, the coherence combustion noise level (CCNL) is calculated from the in-cylinder pressure level and the transfer characteristics $\mathrm{H}$ by equation 2 .

The pressure changes produce vibrations, transfer, and attenuation in the cylinder block, before it is released from the surface of the engine as combustion noise. The frequency characteristics are specific to the engine used. The engine structure attenuation (SA) can be calculated from the coherence combustion noise level and cylinder pressure level by equation 3, it was calculated under several conditions and averaged to provide a representative structure attenuation curve. Figure 4 shows the frequency characteristics of the structure attenuation (SA), and the combustion noise level (CNL) in the engine tests and simulations are calculated from the cylinder pressure level (CPL) and the structure attenuation (SA) by equation 4. (The direct noise measurements in Figure 2 are only conducted to determine the engine transfer function $\mathrm{H}$. Once the structure attenuation is obtained, the combustion noise is calculated by equation 4.) 


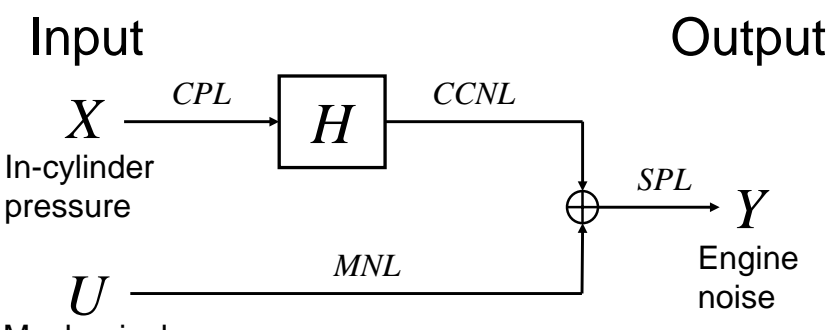

Mechanical

noises

Figure 3. Engine noise generation model

$$
\begin{aligned}
& S P L=C C N L+M N L \\
& C C N L=C P L * H \\
& S A=C C N L-C P L \\
& C N L=S A+C P L
\end{aligned}
$$

$S P L$ : Sound pressurelevel $[d B A]$

CCNL : Combustion noiselevel by cohlent method $[d B A]$

$M N L$ : Mechanical noiselevel [dBA]

$H$ :Transfercharacteristic

$S A$ : Structure attenuation $[d B A]$

$C N L$ : Combustion noise level [ $\mathrm{dBA}]$

$C P L$ : Cylinder pressure level $[d B]$

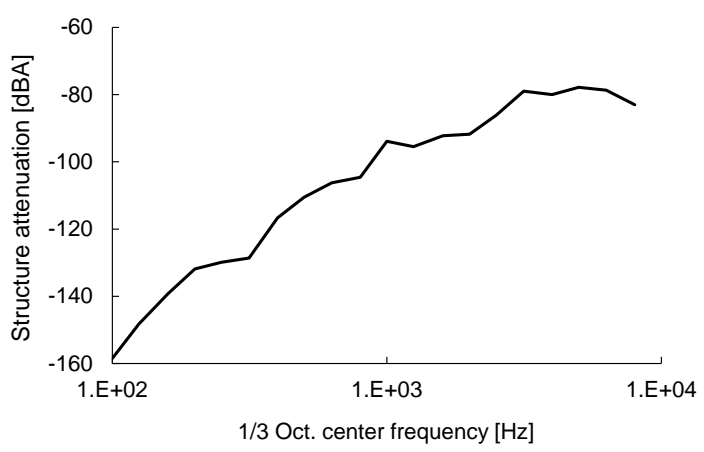

Figure 4. Structural attenuation of the test engine

Figure 5 shows the equal loudness curve of 60 phon pure sound for the human ear. For example, $60 \mathrm{~dB}$ of a $1 \mathrm{kHz}$ pure sound (Point 1 ) is equivalent to $87 \mathrm{~dB}$ of $63 \mathrm{~Hz}$ (Point 2). This curve shows that the sensitivity of the human ear changes with frequency. Typically the sensitivity of the human ear is low below approximately $600 \mathrm{~Hz}$ and above $3000 \mathrm{~Hz}$, and is highest in the $1000-3000 \mathrm{~Hz}$ range. The sensitivity of the human ear changes depending on the frequency range. Therefore, the "A" weighted sound pressure level, the dBA, was used to evaluate the perceived loudness of the overall combustion noise.

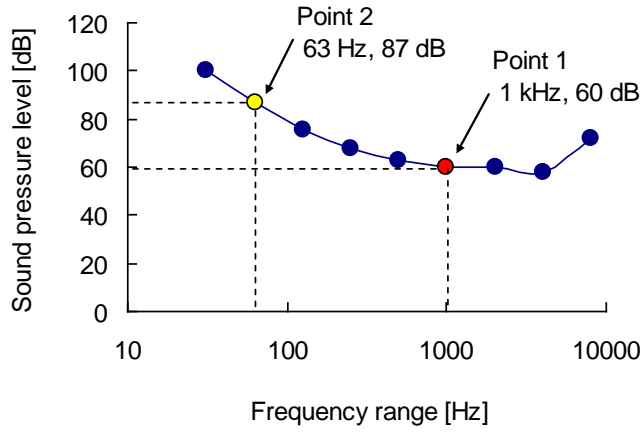

Figure 5. Equal loudness curve of a pure sound at 60 phon for the human ear

\section{Simulation methods}

\section{Wiebe Curve Fitting to Three Stage Combustion}

The heat release histories were approximated by the Wiebe function, the simulated combustion noise was then calculated from the fitted curves of the heat release and the coherence transfer function, as a result the effects of the heat release history on the combustion noise and indicated thermal efficiency were investigated. An example of the heat release shape in three stage injection is shown in Figure 6. The heat release history was synthesized by introducing the Wiebe function in equation 5 four times: one time for the low temperature heat release (LTHR) and one each for the first, second, and third high temperature heat releases (HTHRs). In each of these heat release calculations, the Wiebe functions were fitted to the heat release history of three stage combustion in the engine test and the parameters $M$ and $\theta_{z}$ in Table 2 were obtained and used in the further simulations.

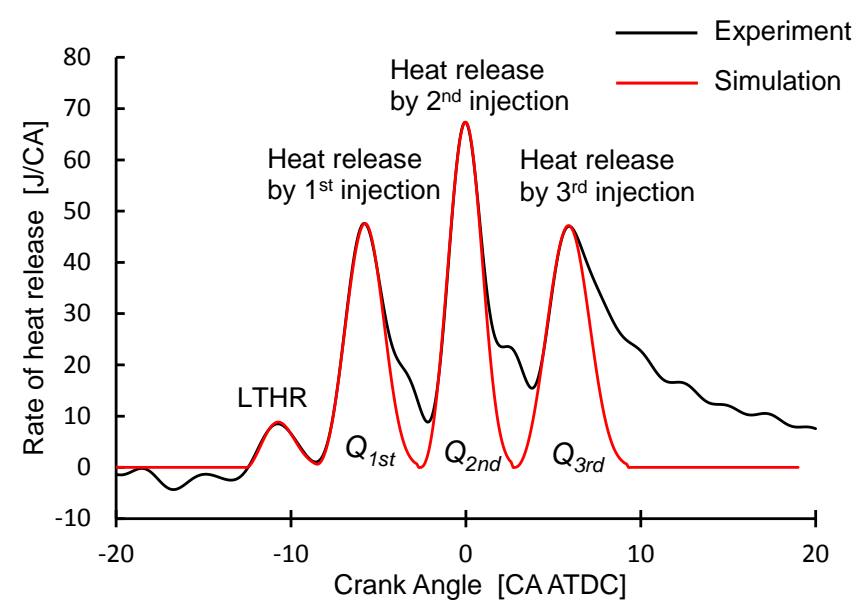

Figure 6. Approximation by the Wiebe function for the three stage combustion

Table 2. The values of parameters $M$ and $\theta_{\mathrm{z}}$ in the Wiebe function for $\mathrm{Q}_{1 \mathrm{st}}$, $\mathrm{Q}_{2 \text { nd }}$ and $\mathrm{Q}_{3 \mathrm{rd}}$

\begin{tabular}{|c|c|c|c|c|}
\hline & LTHR & $\mathrm{Q}_{1 \text { st }}$ & $\mathrm{Q}_{2 \text { nd }}$ & $\mathrm{Q}_{3 \text { rd }}$ \\
\hline $\mathrm{M}$ & 1.5 & 2.15 & 2.2 & 2.1 \\
\hline$\theta_{\mathrm{z}}$ & 4.7 & 5.9 & 5.3 & 6.5 \\
\hline
\end{tabular}

The in-cylinder pressure history was calculated from the heat release history by the Runge-Kutta numerical method in equation 6 , and the kappa is calculated every 0.20 degree of crank angle from the incylinder temperature and the cylinder gas composition. The overall 
combustion noise and frequency characteristics of the combustion noise were calculated from the frequency characteristics of the incylinder pressure by Fourier transformation and the structure attenuation.

$\frac{d Q}{d \theta}=6.9 \cdot \frac{Q_{\text {total }}}{\theta_{Z}} \cdot(M+1) \cdot\left(\frac{\theta}{\theta_{Z}}\right)^{M} \cdot \exp \left\{-6.9 \cdot\left(\frac{\theta}{\theta_{Z}}\right)^{M+1}\right\}$

$Q_{\text {total }}:$ Total heat release $[\mathrm{J}]$

$\theta_{\mathrm{Z}}$ :Combustion duration $\left[{ }^{\circ} \mathrm{CA}\right]$

$M$ : Parameter $M \quad[-]$

$\theta:$ Crank angle $\left[{ }^{\circ} \mathrm{CA}\right]$

$\frac{d Q}{d \theta}=\frac{\kappa}{\kappa-1} \cdot P \cdot \frac{d V}{d \theta}+\frac{1}{\kappa-1} \cdot V \cdot \frac{d P}{d \theta}$

$Q:$ Heat release $[\mathrm{J}]$

$\kappa:$ Ratio of specific heats [-]

$P$ : Pressure [Pa]

$V:$ Volume $\left[\mathrm{m}^{3}\right]$

$\theta:$ Crank angle $\left[{ }^{\circ} \mathrm{CA}\right]$

To evaluate the accuracy of the simulation data, the combustion data obtained by engine test experiments and simulations were compared. The heat history of the engine data and the approximate history of the heat release by the Wiebe function are plotted together in Figure 7 , and the combustion noise data of the experiments and simulation at $100-8000 \mathrm{~Hz}$ are plotted in Figure 8. The frequency characteristics of the simulation were very similar to the experiments, and this verifies that the combustion noise could be evaluated by the simulation.

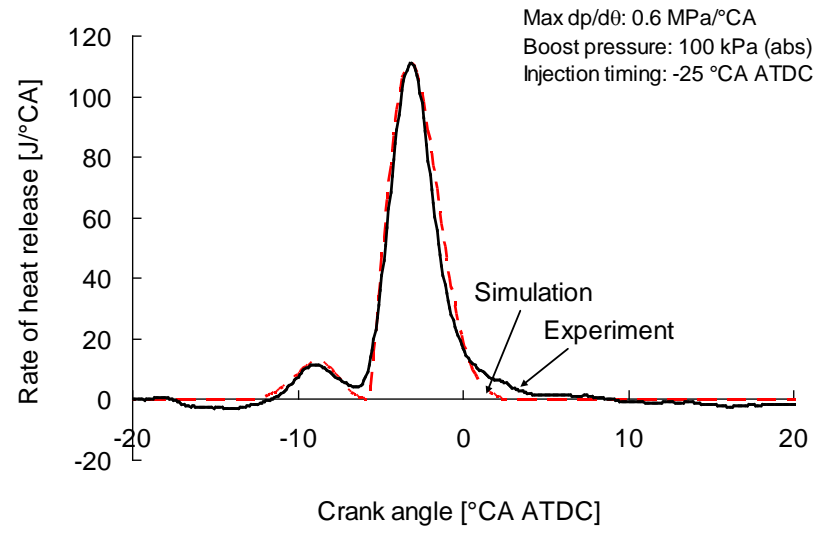

Figure 7. Heat release data in experiment and simulation

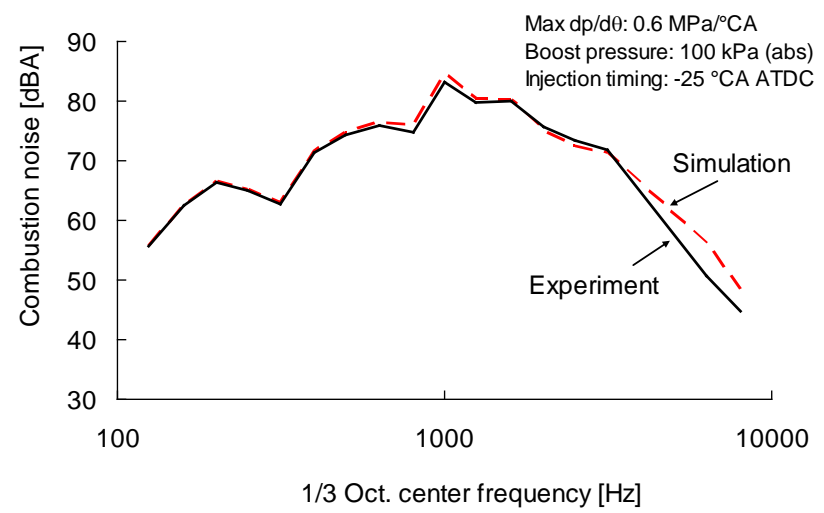

Page 4 of 15
Figure9 shows a rate of heat release and rate of pressure rise in two stage combustion and Figure 10 shows an explanation of amplifying and reduction phenomenon of combustion noise. The time difference in the crank angle at the peaks of the pressure rise rates between the first and second fuel injections is defined as $d P / d \theta_{1-2}$ in Figure 9. Equations 7 and 8 show the amplifying and reduction frequencies between Peaks 1 and 2 . The $\Delta t$ in the equations is the duration (sec) of $d P / d \theta_{1-2}$, and $\Delta$ t equals $\left(d P / d \theta_{1-2}\right) / 12000$ as the engine is operated at $2000 \mathrm{rpm}$.

Amplifying frequency $[\mathrm{Hz}]: f n=n_{A} / \Delta t$

$\left(n_{A}=1,2,3, \cdots\right)$

Reduction frequency $[\mathrm{Hz}]: f n=\left(2 n_{C}+1\right) / 2 \Delta t$

$\left(n_{C}=0,1,2,3 \cdots\right)$
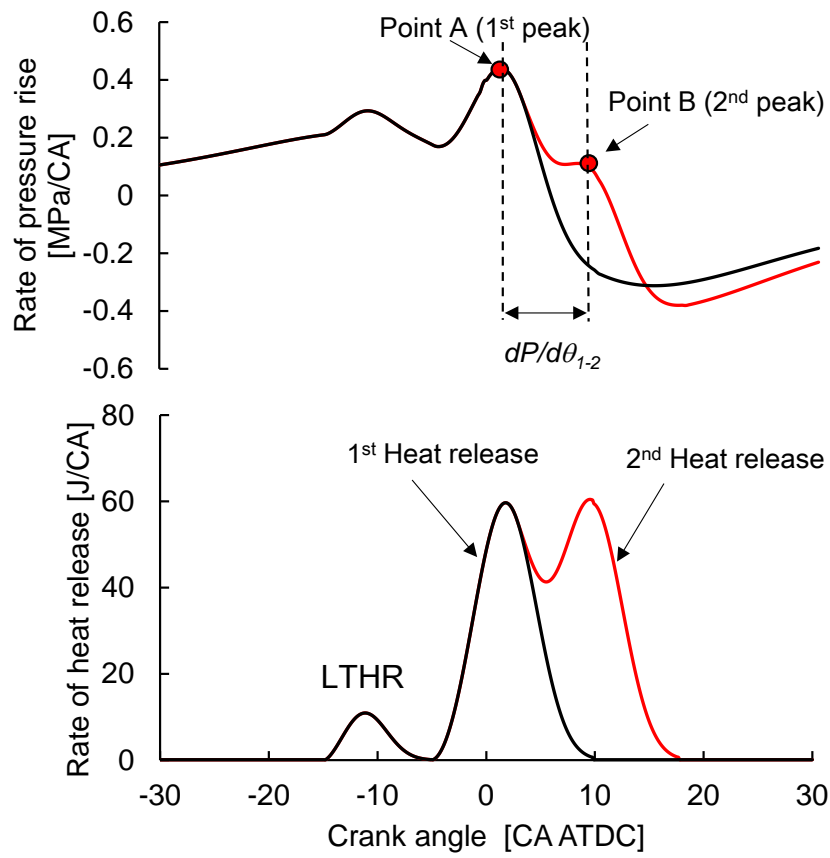

Figure 9. Heat release and pressure rise data in two stage combustion

As shown in equation 4, the combustion noise (CNL) is consisted from structure attenuation (SA) and cylinder pressure level (CPL). The SA is specific and constant for the test engine, and the changes in combustion noise is caused by the CPL. Here, the combustion noise in two stage combustion was explained by the CPL in Figure 10, and the frequencies of noise amplification and reduction by the interferences of two stage combustion noises appear in a cyclic manner. If the noise reduction can be done at the loudest frequency range for the engine, the overall combustion noise can be reduced. This is the basic idea of the two stage NCS combustion. 


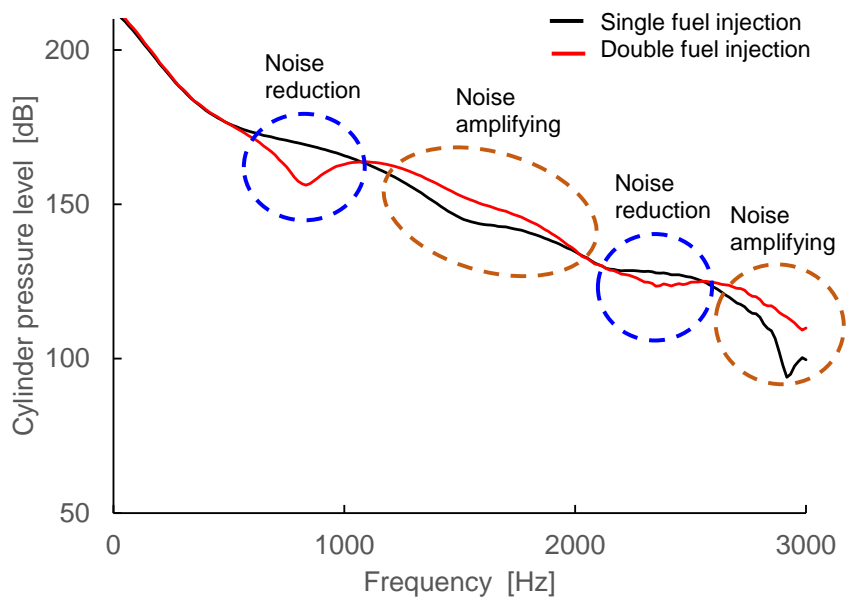

Figure 10. Parameter variables in the simulations

For the three stage combustion in Figure 11, the interferences of combustion noise in Peaks 1-2, Peaks 2-3, and Peaks 1-3 appear, and the combustion noise can be reduced by changing the duration of $d P / d \theta_{1-2}, d P / d \theta_{2-3}$, and $d P / d \theta_{1-3}$ and the heating value ratio between Q1, Q2 and Q3. It is investigated in Tests 2-4. This effect is investigated in Tests 2-4.

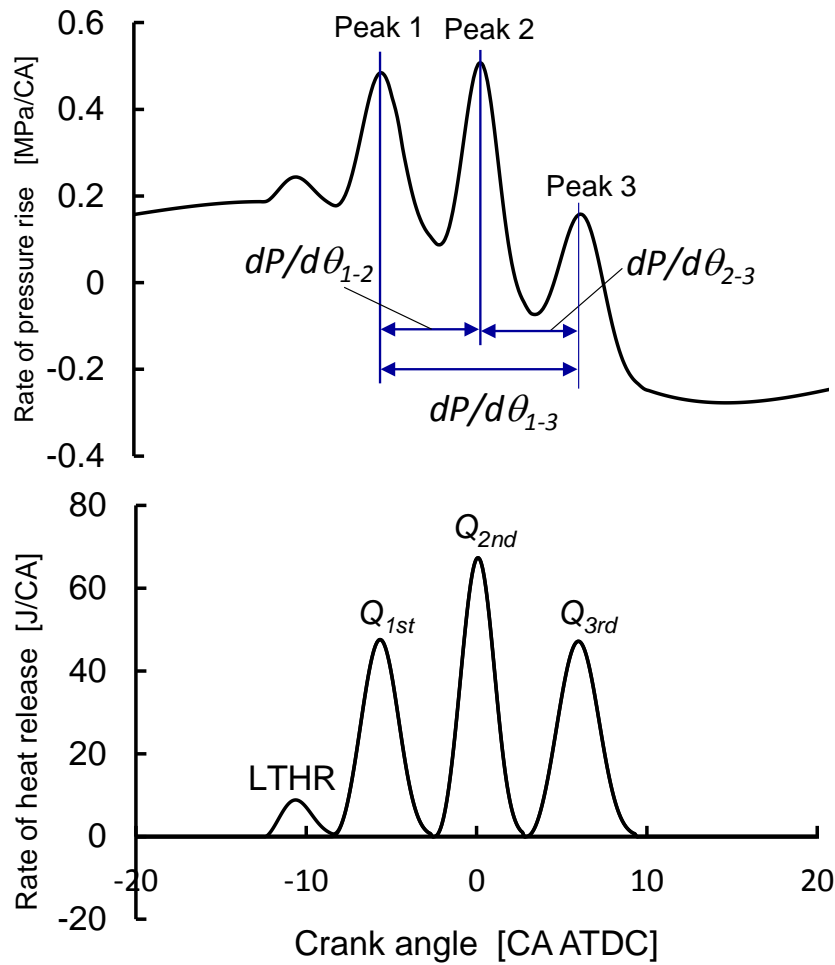

Figure 11. Parameter variables in the simulations

\section{Method of the Indicated Thermal Efficiency Calculations}

The cylinder gas composition at each crank angle is calculated for the simulated heat release history. This allows the pressure, mean temperature, specific heats, specific heat ratios, and generated work to be calculated for the expansion stroke. The cooling loss is calculated by the Hohenberg equation and the cylinder temperature from the IVC to the EVO timings (the Woschni equation was Page 5 of 15 considered, but the Hohenberg equation was found to agree better with the engine test data here). The exhaust heat loss is calculated from the enthalpy difference between the intake and exhaust gases. The input energy is the total of the integral of the heat release rate and the cooling loss. Altogether this made it possible to calculate the indicated thermal efficiency.

\section{Definition of Parameters in the Simulations}

An example of the history of the rates of heat release and pressure rise calculated by simulation is shown in Figure 11. The heat releases by the three injections were defined as the $Q_{1 s t}, Q_{2 n d}$, and $Q_{3 r d}$. The time differences in the crank angle at the peaks of the pressure rise rates in the first-second heat releases, first-third heat releases, and second-third heat releases were defined as the $d P / d \theta_{1-2}, d P / d \theta_{1-3}$, and $d P / d \theta_{2-3}$ respectively.

\section{Test Conditions for Simulations and Engine Tests}

All the engine tests and simulations are conducted at $2000 \mathrm{rpm}$ in engine speed.

\section{Test 1: Combustion Noise Reduction by the Two Stage Fuel Injection (Engine Tests)}

The effects of the combustion before the TDC, the compression process, and after the TDC, the expansion process, on the degree of constant volume and combustion noise reduction by the NCS (noise cancelling spike) were investigated. Figure 12 (a) is termed early two stage combustion: the crank angle of the peak heat release in the first fuel injection is before the TDC and the crank angle of the peak heat release in the second fuel injection is at the TDC. Figure 12 (b) is named late two stage combustion: the crank angle of the peak heat release in the first fuel injection is at the TDC and the crank angle of the peak heat release in the second fuel injection is after the TDC.

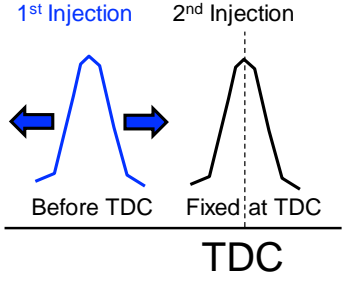

(a) Early two stage combustion

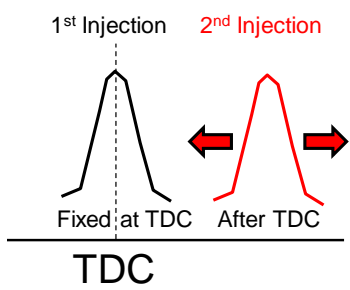

(b) Late two stage combustion
Figure 12. Definitions of (a) the early two stage and (b) late two stage combustions

The test conditions are shown in Table 3 . The engine was operated at $2000 \mathrm{rpm}$, and four types of engine tests were conducted.

\section{(1) Single Heat Release Test}

The crank angle of the peak heat release was at the TDC and the IMEP was $0.35 \mathrm{MPa}$. This is the basic condition of premixed diesel combustion.

(2) Late two stage Combustion (Heat release phases: Figure 12 (b))

The electrical signal was given to the ECU (Engine control unit) of the common rail system to ensure equal heating values in the first and second heat releases, and the timing of the start of the second 
injection was retarded from -4.0 to +2 CA ATDC, maintaining an $0.70 \mathrm{MPa}$ of IMEP. The effects of the two stage combustion on the combustion noise and degree of constant volume were investigated.

\section{(3) Late two stage Combustion (Equal maximum rates of heat release in the first and second combustions)(Heat release phases: Figure 12 (b))}

In the late two stage combustion, the second combustion may become diffusion combustion in the expansion stroke, and the combustion noise reduction by NCS effect is small. To avoid this, the second heat release was increased and the first heat release was reduced a similar amount to maintain the equal maximum rate of heat releases (80 $\mathrm{J} / \mathrm{CA}$ ) for the first and second combustions. The IMEP was maintained at $0.7 \mathrm{MPa}$ and the SOI (start of injection) of the second fuel injection was -4.0 CA ATDC.

\section{(4) Early two stage Combustion (Heat release phases: Figure 12} (a))

The maximum rate of heat release in the second fuel injection was maintained at $80 \mathrm{~J} / \mathrm{CA}$, and the SOI timing of the first injection was at -19.5 CA ATDC or -18.5 CA ATDC. The fuel quantity of the first injection was varied to maintain $0.7 \mathrm{MPa}$ of IMEP.

Table 3. Operational conditions for two stage combustion

\begin{tabular}{|c|c|c|c|c|c|c|}
\hline \multirow{3}{*}{ Test name } & \multirow{3}{*}{$\begin{array}{l}\text { Combustion } \\
\text { phase }\end{array}$} & \multirow{2}{*}{ IMEP } & \multicolumn{2}{|c|}{ 1st Fuel injection } & \multicolumn{2}{|c|}{ 2nd Fuel injection } \\
\hline & & & $\mathrm{SOl}^{*}$ & Duration* & $\mathrm{SOI}^{*}$ & Duration* \\
\hline & & Mpa & CAATDC & msec & CAATDC & $\mathrm{msec}$ \\
\hline Test 1-(1) & Single & 0.35 & \begin{tabular}{|l|}
-15.50 \\
\end{tabular} & 0.280 & - & - \\
\hline \multirow{4}{*}{ Test 1-(2) } & \multirow{5}{*}{$\begin{array}{l}\text { Reat two } \\
\text { stage }\end{array}$} & \multirow{7}{*}{0.70} & -12.25 & 0.261 & -4.00 & 0.258 \\
\hline & & & -13.25 & 0.261 & -2.00 & 0.313 \\
\hline & & & -13.50 & 0.261 & 0.00 & 0.333 \\
\hline & & & -13.25 & 0.261 & 2.00 & 0.275 \\
\hline Test1-(3) & & & -12.75 & 0.233 & -4.00 & 0.280 \\
\hline \multirow{2}{*}{ Test1-(4) } & \multirow{2}{*}{$\begin{array}{l}\text { Front two } \\
\text { stage }\end{array}$} & & -19.50 & 0.218 & -8.75 & 0.330 \\
\hline & & & -18.50 & 0.230 & -8.00 & 0.314 \\
\hline
\end{tabular}

These test results are arranged by the degree of constant volume and combustion noise rather than by thermal efficiency, because the IMEPs of the single injection and two stage combustions were different.

\section{Test 2: Effects on Combustion Noise of the Three Stage Combustion near the TDC (Simulation)}

To investigate the mechanism of multiple fuel injections on the reduction of combustion noise, a three stage combustion near the TDC was attempted by simulation. In Figure 13 the red curve shows the optimum heat release shape for the late two stage combustion calculated by simulation [13], and one more heat release was added ahead of the following two stage combustion. The heating value of the first heat release is a parameter variable varied from $100 \mathrm{~J}$ to 500 $\mathrm{J}$, with the $d P / d \theta_{1-2}$ and $d P / d \theta_{2-3}$ maintained $3 \mathrm{CA}$.
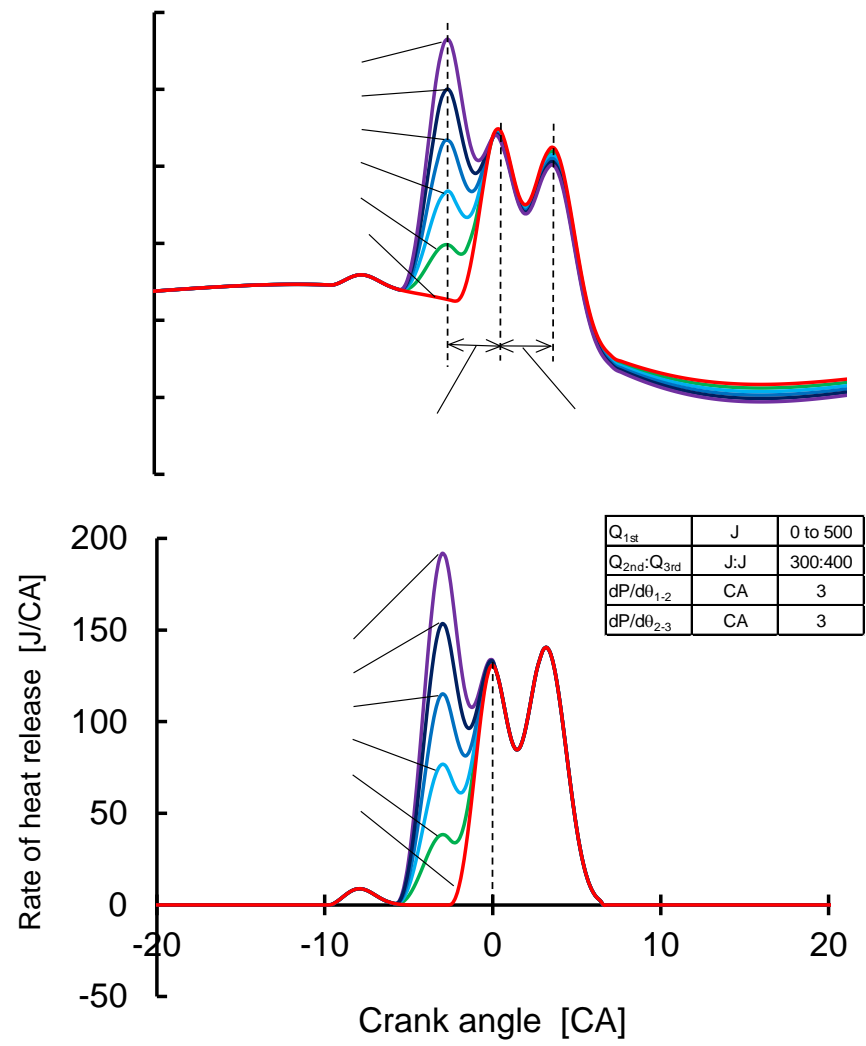

Figue 13. The simulation method in Test 2

The optimization of the triple phase combustion was investigated by the simulation in Test 3 and compared with the actual engine tests in Test 4 .

Test 3: Optimization of the Heat Release Shape for Low Combustion Noise and High Thermal Efficiency in Three Stage Combustion (Simulation)

In this simulation, the IMEP was maintained at $0.56 \mathrm{MPa}$, and the crank angle of the peak heat release in the second fuel injection was set at TDC. In each of the heat releases, the $M$ and $\theta_{z}$ in the Wiebe functions were the same as shown in Table 2. The parameter variables in the simulations were as follows:

(1) The length of time in crank angle between the peaks of the rate of pressure rise in Peaks 1 and $2\left(d P / d \theta_{1-2}\right)$ was varied from 3 to 5 CA

(2) The length of time in crank angle between the peaks of the rate of pressure rise in Peaks 2 and $3\left(d P / d \theta_{2-3}\right)$ was varied from 3 to 7 CA

(3) The heating values for the $Q_{1 s t}, Q_{2 n d}$, and $Q_{3 r d}$

a) The total amount of $Q_{1 s t}, Q_{2 n d}$, and $Q_{3 r d}$ is $585 \mathrm{~J}$.

b) The $Q_{1 s t}$ value was varied from $75 \mathrm{~J}$ to $435 \mathrm{~J}$ in $40 \mathrm{~J}$ steps.

c) The $Q_{2 n d}$ value was varied from $75 \mathrm{~J}$ to $275 \mathrm{~J}$ in $40 \mathrm{~J}$ steps.

d) The $Q_{3 r d}$ value was $585 \mathrm{~J}$ minus the sum of the $Q_{1 s t}$ and $Q_{2 \text { nd }}$ values.

$\left(Q_{3 r d}=585-Q_{1 s t}-Q_{2 n d}\right.$ and $\left.Q_{3 r d} \geq 75 \mathrm{~J}\right)$

The details of the heat release shape in the three stage combustion are shown in Figure 14. 


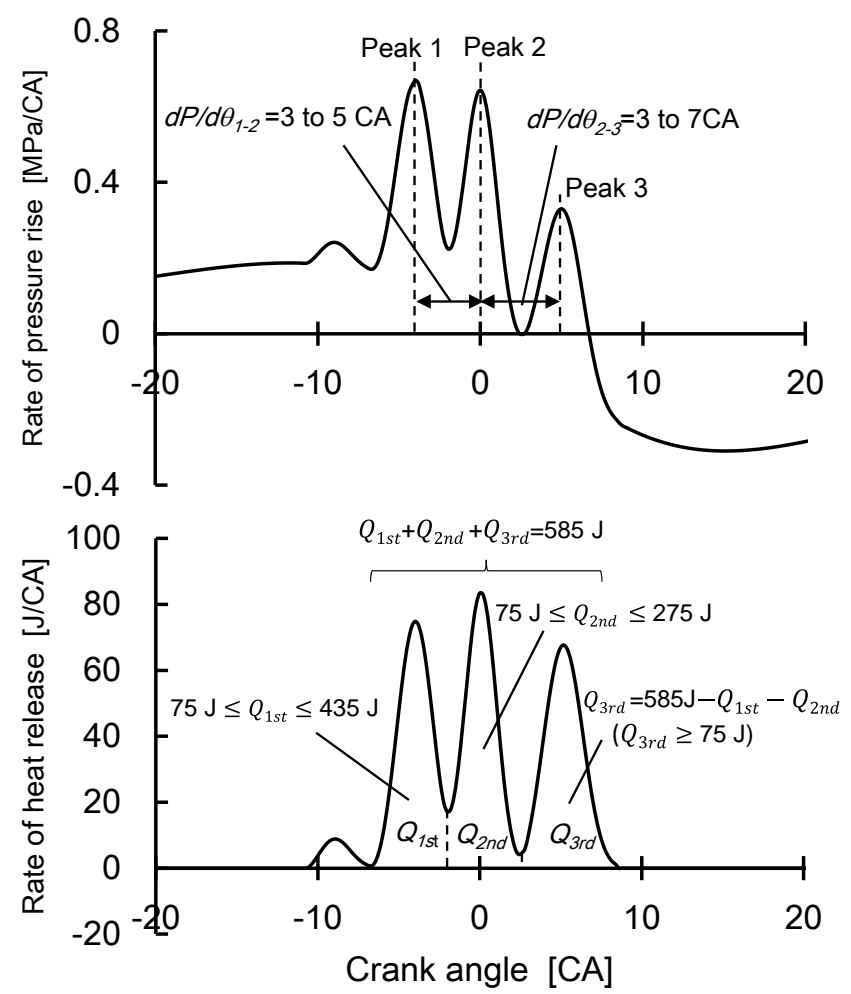

Figure 14. Parameter variables for the simulations in Test 3

\section{Test 4: Evaluation of Accuracy of the Simulation Results in Test 3 by Engine Tests}

The accuracy of the simulation results was evaluated by the engine test. With the test engine, the first and second heat releases show premixed diesel combustion, however the third heat release may become diffusion combustion in the three stage combustion (Appendix 2). To further investigate this, the engine was operated with three types of two stage combustion $\left(\operatorname{Twin}_{1-2}, \mathrm{Twin}_{2-3}\right.$, and Twin $_{1-3}$ ) representing the optimum three stage combustion in Test 2, as shown in Figure 15, and the combustion noise reduction of the three stage combustion was determined with the data of the two stage combustions.

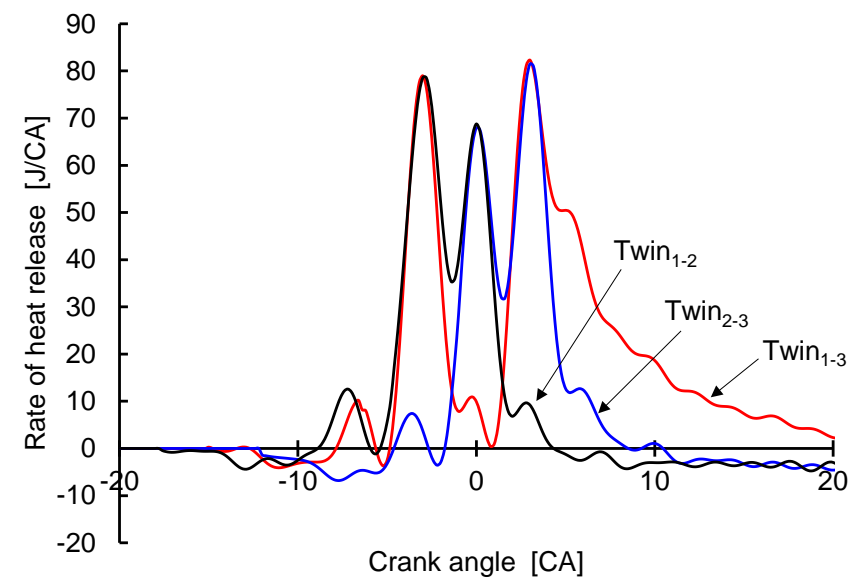

Figure 15. Two stage combustions in Test $3\left(\operatorname{Twin}_{1-2}, \operatorname{Twin}_{2-3}\right.$, and $\left.\operatorname{Twin}_{1-3}\right)$
Test 5: Effects of Multistage Combustion on the Indicated Thermal Efficiency and Combustion Noise (Simulation)

The optimum heat release shapes of the single stage, two stage, and three stage HTHR combustions for combustion noise and degree of constant volume were calculated and the multistage combustion effects are discussed.

\section{Results and Discussion}

\section{Test 1: Combustion Noise Reduction by the Two Stage Fuel Injections (Engine Tests)}

Figure 16 plots the overall combustion noise vs the degree of constant volume for two stage fuel injections in Test 1, and Figure 17 shows the rate of pressure rise in late two stage combustion (Test 1(2)). When the second fuel injection timing was 2 CA ATDC, the overall combustion noise was 92.7dBA. With the earlier start timing of the second fuel injection, the degree of constant volume increased, the maximum rate of pressure rise of the second fuel injection increased as in Figure 17, and the combustion noise was reduced 0.7 dBA by the noise cancelling spike (NCS) effect as in Figure 16. When the second injection timing was -4 CA ATDC, the peaks of the maximum rates of pressure rise $\left(\Delta \mathrm{t}=d P / d \theta_{1-2}\right)$ is $3.3 \mathrm{CA}$. In Table 4 , the amplifying and reduction frequencies are listed, and it shows that the combustion noise at $1500-2000 \mathrm{~Hz}$ is reduced and the combustion noise at $3000-4000 \mathrm{~Hz}$ is amplified, calculated by the equations 7 and 8. Comparing the black and red lines in Figure 19, the combustion noise at $1600 \mathrm{~Hz}$ was reduced but increase at $3150 \mathrm{~Hz}$ in black line, and it was proved that the combustion noise frequency can be controlled by the peak duration of the maximum rate of pressure rises $\left(\Delta \mathrm{t}=d P / d \theta_{1-2}\right)$.

In Test 1-(3), the peak of the first heat release was reduced to 80 $\mathrm{J} / \mathrm{CA}$ by the reduction of the first fuel injection quantity and the heating value of the second injection was increased maintaining the IMEP of $0.7 \mathrm{MPa}$, as shown by the blue curve in Figure 18 . The combustion noise was reduced to $89.1 \mathrm{dBA}$ (the red triangle plot in Figure 16), and the combustion noise at $600-3000 \mathrm{~Hz}$ was reduced substantially (blue line) as shown in Figure 19, due to the reduction in the maximum rate of pressure rise in the first combustion and the stronger NCS effect.

Figure 20 shows the rates of pressure rise of the early two stage combustion in Test 1-(4). When the start of the first injection was at 18.5 CA, the maximum rates of pressure rise of the first and second injections were similar, and the combustion noise was $87.7 \mathrm{dBA}$ maintaining the degree of constant volume as shown in Figure 16. The frequency characteristics of early two stage combustion in Test 1-(4) is shown in Figure 21. The combustion noise at $3000 \mathrm{~Hz}$ in the early two stage combustion (Figure 21) is lower than those of the late two stage combustions in Figure 19. In the early two stage combustion, the first heat release occurs in the compression stroke and the high maximum rate of pressure rise in the first heat release reduces the combustion noise of the second heat release by the NCS effect. In the late two stage combustion, the second combustion occurs in the expansion stroke, the maximum rate of pressure rise in the second combustion is low, and the combustion noise reduction by the NCS effect of late two stage combustion is lower than that of early two stage combustion. 


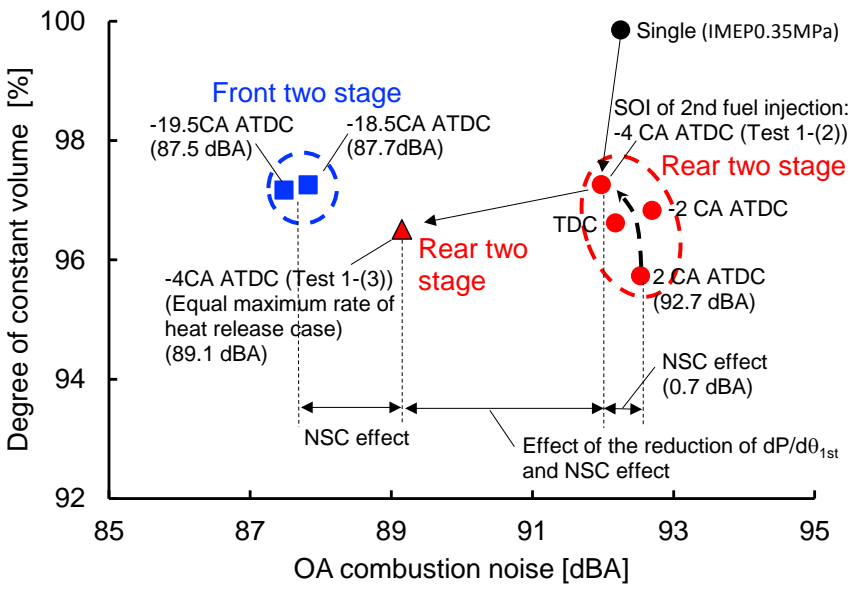

Figure 16. Overall combustion noise vs degree of constant volume for Test 1

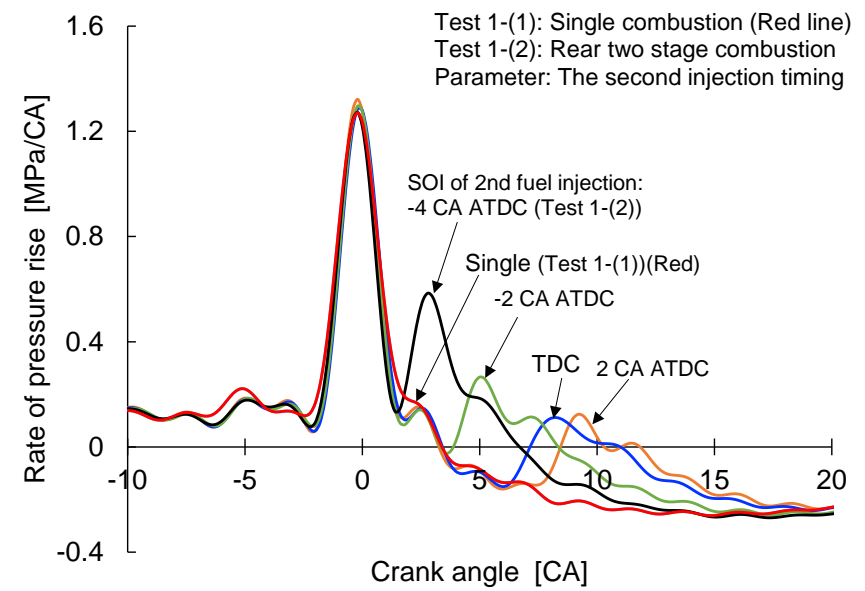

Figure 17. Changes in the rate of pressure rise by the second fuel injection timing (Test 1-(2))

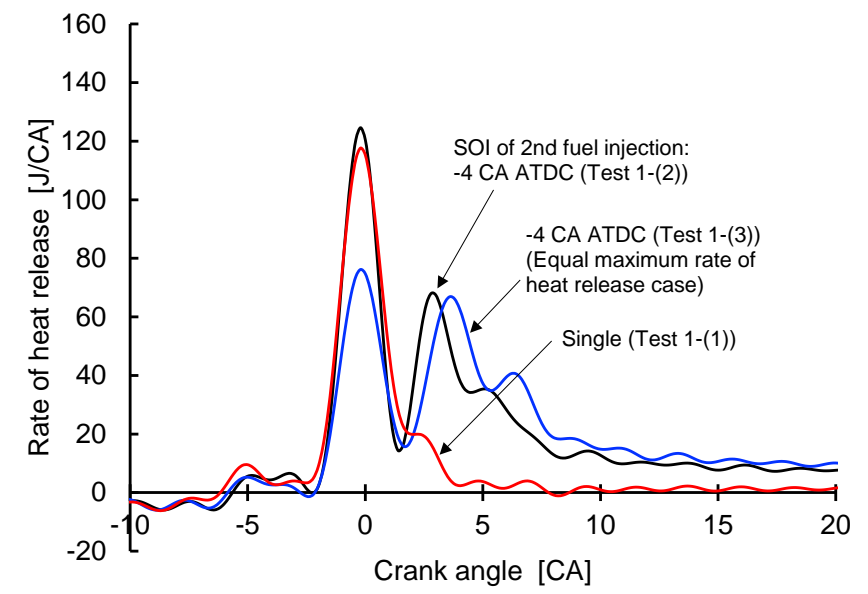

Figure 18. The rates of heat releases in single (Test 1-(1)) and late two stage combustions (Test1-(2) and (3))

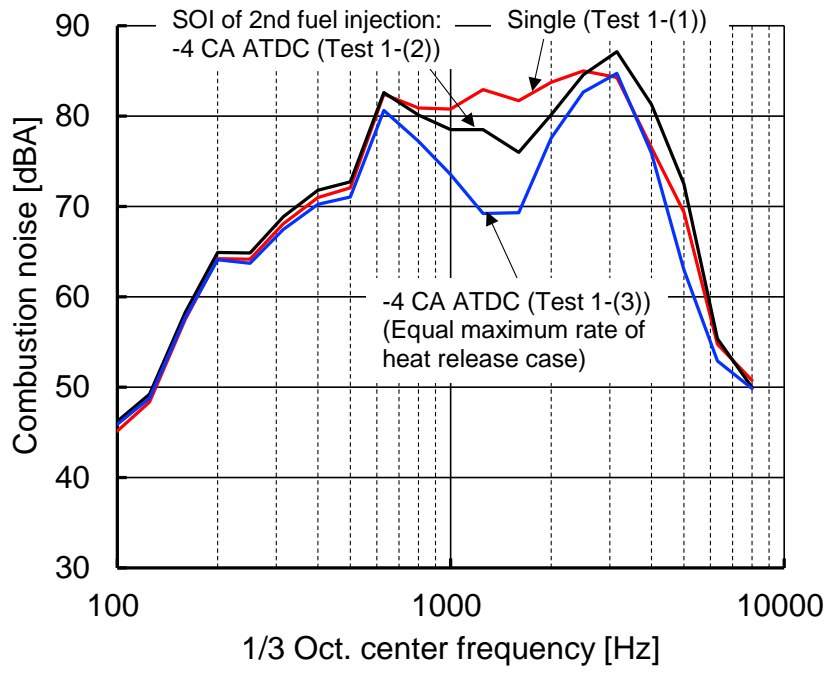

Figure 19. Frequency characteristics of single (Test 1-(1)) and late two stage combustions (Test1-(2) and (3))

Table 4. Length of time in crank angle between the peaks of the rates of the pressure rise vs amplifying frequency and cancelling frequency

\begin{tabular}{|c|c|c|c|c|c|}
\hline \multicolumn{2}{|c|}{$\Delta \mathrm{t}\left(d P / d \theta_{1-2}\right.$ or $\left.d P / d \theta_{2-3}\right)$} & \multicolumn{2}{|c|}{ Amplifying frequency } & \multicolumn{2}{c|}{ Reduction frequency } \\
\hline $\mathrm{CA}$ & $\mathrm{msec}$ & \multicolumn{2}{|c|}{$\mathrm{Hz}$} & \multicolumn{2}{c|}{$\mathrm{Hz}$} \\
\hline 3 & 0.25 & 8000 & 4000 & 2000 & 6000 \\
\hline 4 & 0.33 & 6000 & 3000 & 1500 & 4500 \\
\hline 5 & 0.42 & 4800 & 2400 & 1200 & 3600 \\
\hline 6 & 0.5 & 4000 & 2000 & 1000 & 3000 \\
\hline 7 & 0.58 & 3429 & 1714 & 857 & 2571 \\
\hline 8 & 0.67 & 3000 & 1500 & 750 & 2250 \\
\hline 9 & 0.75 & 2667 & 1333 & 667 & 2000 \\
\hline 10 & 0.83 & 2400 & 1200 & 600 & 1800 \\
\hline 11 & 0.92 & 2182 & 1091 & 545 & 1636 \\
\hline
\end{tabular}

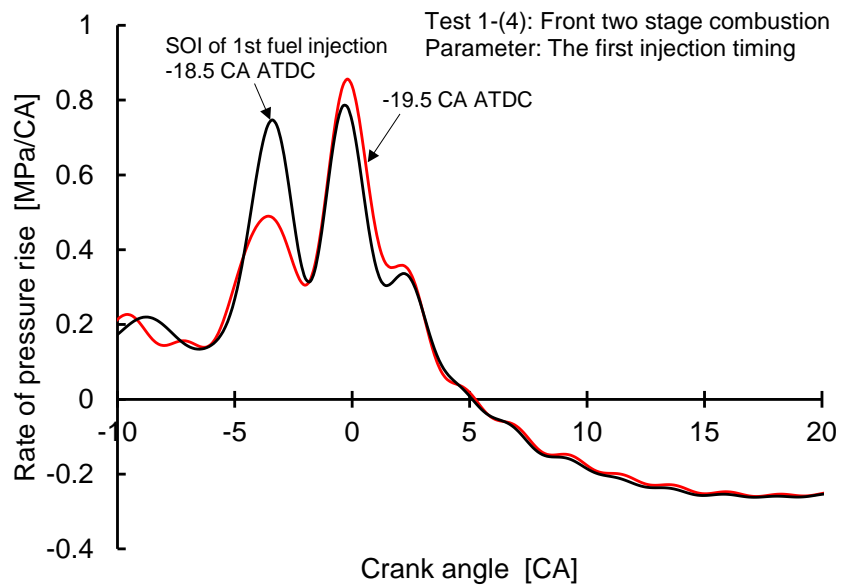

Figure 20. Rates of pressure rise in early two stage combustions (Test 1-(4)) 


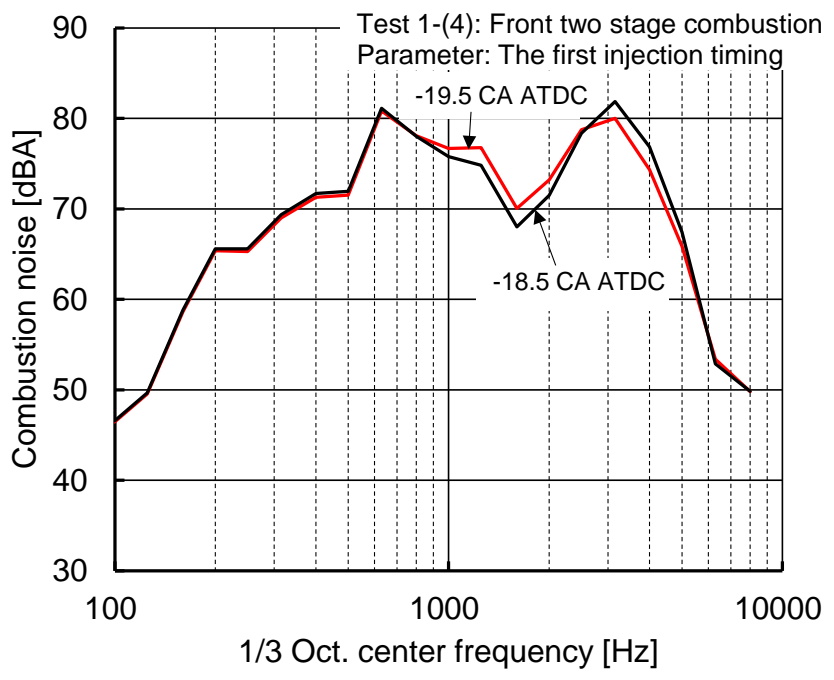

Figure 21. Frequency characteristics of late two stage combustions (Test 1(4))

\section{Test 2: Effects on Combustion Noise of the Three Stage Combustion near the TDC (Simulation)}

To investigate the mechanism of multiple fuel injections on the reduction of combustion noise, three stage combustion near the TDC was simulated. Here, one heat release was added ahead of the optimum two stage combustion for low engine noise and the heating value of the first heat release was varied from $100 \mathrm{~J}$ to $500 \mathrm{~J}$, as shown in Figure 13. Figure 22 plots the overall combustion noise versus the indicated mean effective pressure. The overall combustion noise reduces by the NCS effect. When the first heating value is $200 \mathrm{~J}$, the overall combustion noise is $1.2 \mathrm{dBA}$ lower than that of the two stage combustion (the $0 \mathrm{~J}$ case), and the overall combustion noise increased with the increase in the first heating value above $200 \mathrm{~J}$.

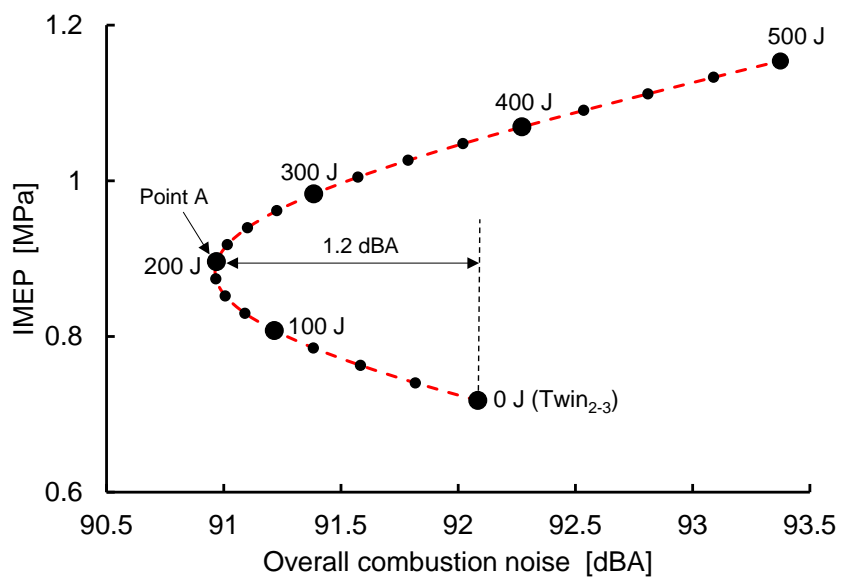

Figure 22. The overall combustion noise vs IMEP in Test 2

The blue curve in Figure 23 shows the three stage combustion at Point A in Figure 22, the lowest overall combustion noise condition, and the three stage heat release was disassembled into two sets of two stage heat releases, the $\mathrm{Twin}_{2-3}$ and $\mathrm{Twin}_{1-3}$, to investigate the reduction and amplifying frequencies of combustion noise further.

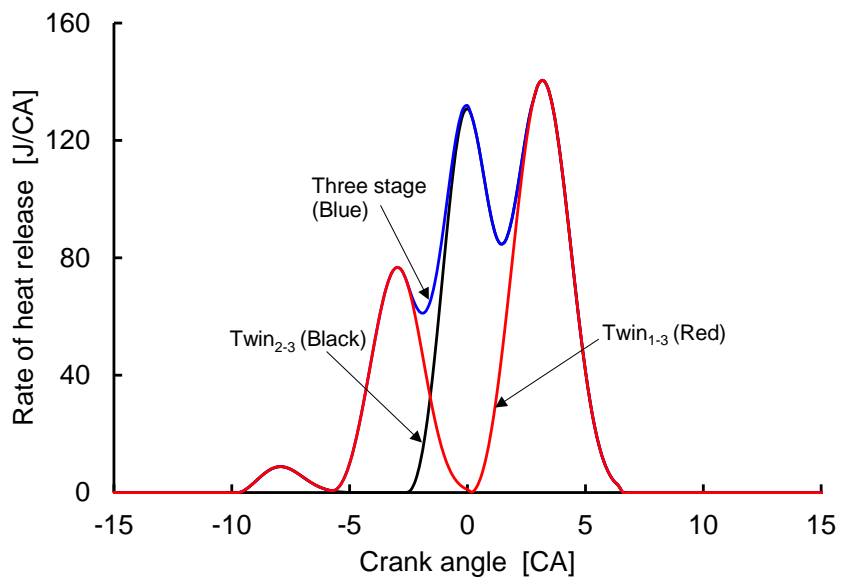

Figure 23. Three stage combustion at Point A in Figure 22 and two sets of two stage heat releases, $\operatorname{Twin}_{2-3}$ and $\operatorname{Twin}_{1-3}$

In equation 4 , the combustion noise level (CNL) is comprised of the structure attenuation (SA) and the cylinder pressure level (CPL). The SA is specific and constant for the tested engine, and the changes in combustion noise would be caused by the CPL. Figure 24 plots the CPL for the three stage combustion and two sets of two stage combustions ( $\operatorname{Twin}_{1-3}$ and $\operatorname{Twin}_{2-3}$ ), and the frequency characteristics of the combustion noises by these three combustions are shown in Figure 25. The amplifying frequency and the frequency where $\mathrm{Twin}_{1-}$ 3 is reduced are around $2000 \mathrm{~Hz}$ and $1000 \mathrm{~Hz}$ respectively, and the frequency of $\mathrm{Twin}_{2-3}$ reduction is around $1900 \mathrm{~Hz}$. The amplifed frequency of $\mathrm{Twin}_{1-3}$ overlaps the frequency where Twin $2-3$ is reduced and the cylinder pressure level of the three stage combustion is reduced around $2000 \mathrm{~Hz}$ (blue dotted curve in Figure 24). Figure 25 shows that there is a reduction in combustion noise around 2000 $\mathrm{Hz}$.

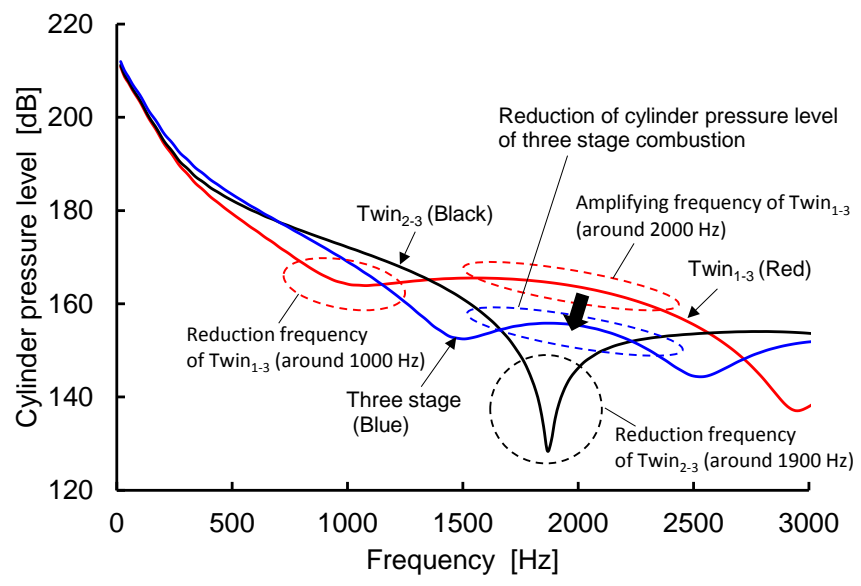

Figure 24. Cylinder pressure level of the three stage combustion and two sets of two stage heat releases, $\operatorname{Twin}_{2-3}$ and $\operatorname{Twin}_{1-3}$, in Figure 23 


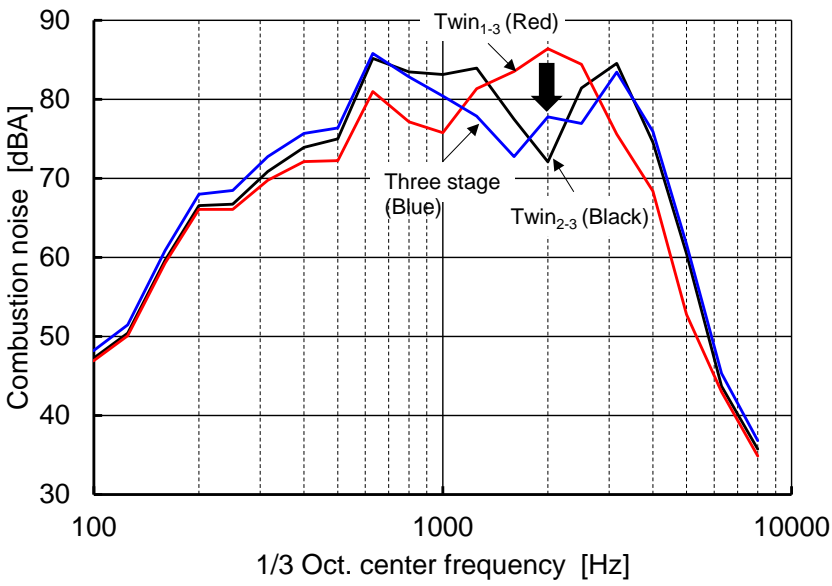

Figure 25. Frequency characteristics of three stage combustion and two sets of two stage heat releases, $\operatorname{Twin}_{2-3}$ and Twin $_{1-3}$, in Figure 23

\section{Test 3: Optimization of the Heat Release Shape for Low Combustion Noise and High Thermal Efficiency in Three Stage Combustion (Simulation)}

The length of time in crank angle between the peaks of the rate of pressure rise in Peaks 1 and $2\left(d P / d \theta_{1-2}\right)$, the length of time in crank angle between the peaks of the rate of pressure rise in Peaks 2 and 3 $\left(d P / d \theta_{2-3}\right)$, and the heating values $Q_{1 s t}, Q_{2 n d}$, and $Q_{3 r d}$ in Figure 14 were the parameters that were varied in the simulations. An example of the simulation results is shown in Figure 26, here $Q_{2 n d}=155 \mathrm{~J}$ and $d P / d \theta_{1-2}=3 \mathrm{CA}$, and the $d P / d \theta_{1-2}$ and the heating values of $Q_{1 s t}, Q_{2 n d}$, and $Q_{3 r d}$ were as noted in the figure. The overall combustion noise is the lowest when $Q_{1 s t}: Q_{2 n d}: Q_{3 r d}=195 \mathrm{~J}: 155 \mathrm{~J}: 235 \mathrm{~J}$. The reason why these optimum heating values result in the lowest combustion noise is that the third combustion occurs in the expansion stroke, and as $Q_{3 r d}$ has to be higher than $Q_{1 s t}$ and $Q_{2 n d}$ to achieve the noise cancelling effects. Further, $Q_{1 s t}$ is effective in lowering the combustion noise at around $1500 \mathrm{~Hz}$.

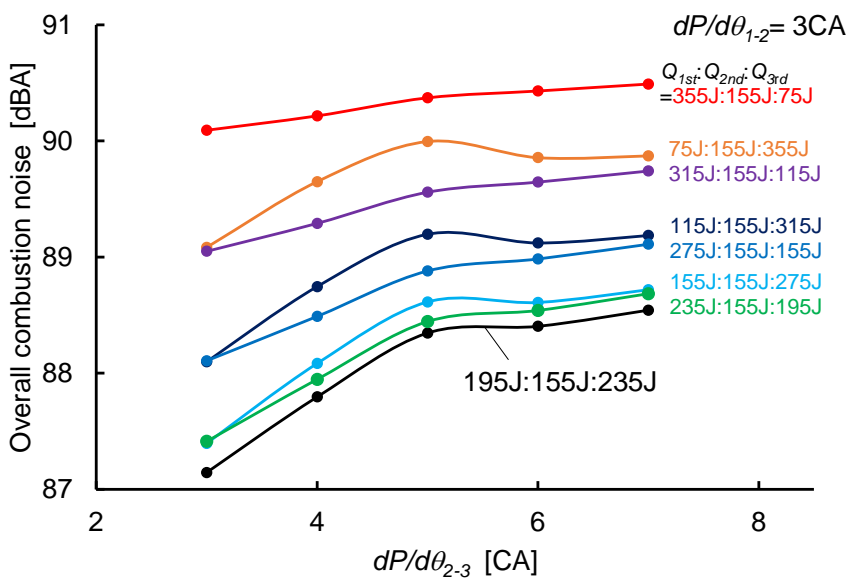

Figure 26. The length of time in crank angle between the peaks of the rates of the pressure rise in Peaks 2 and $3\left(d P / d \theta_{2-3}\right)$ vs overall combustion noise

The length of time in crank angle between the peaks of the rate of pressure rise in Peaks 1 and $2\left(d P / d \theta_{1-2}\right)$ and the length of time in crank angle between the peaks of the rate of pressure rise in Peaks 2 and $3\left(d P / d \theta_{2-3}\right)$ were changed maintaining the

Page 10 of 15
$Q_{1 s t}: Q_{2 n d}: Q_{3 r d}=195 \mathrm{~J}: 155 \mathrm{~J}: 235 \mathrm{~J}$, as shown in Figure 27. The combustion noise was the lowest when the $d P / d \theta_{1-2}=d P / d \theta_{2-3}=3 \mathrm{CA}$.

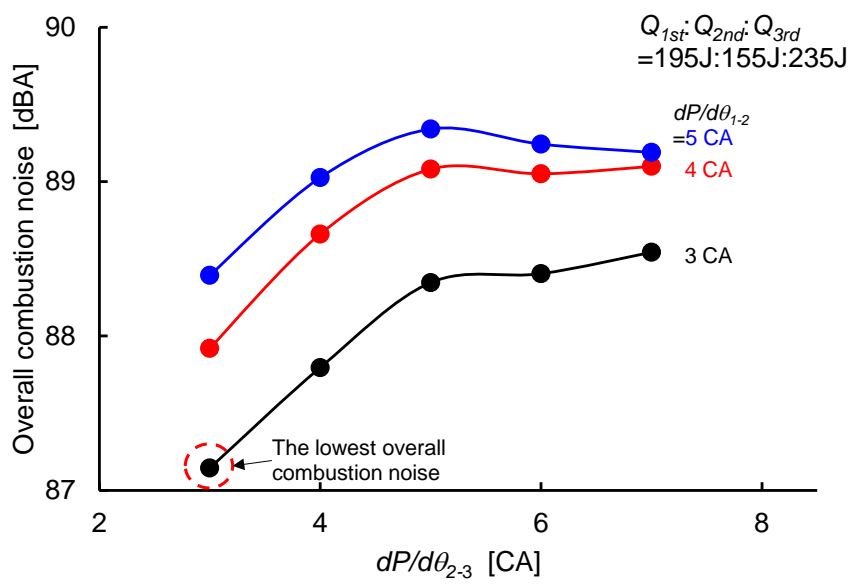

Figure 27. Effects of the length of time in crank angle between the peaks of the rates of pressure rise in Peaks 1 and $2\left(d P / d \theta_{1-2}\right)$ and between the peaks of the rates of pressure rise in Peaks 2 and $3\left(d P / d \theta_{2-3}\right)$ on overall combustion noise

Table 4 shows the amplifying frequency (light blue column) and cancelling frequency (light yellow column) versus the length of time in crank angle between the peaks of the maximum rates of pressure rise $(\Delta \mathrm{t})$. When $\Delta \mathrm{t}=3 \mathrm{CA}$, the amplifying frequencies are $8000 \mathrm{~Hz}$ and $4000 \mathrm{~Hz}$, higher than $3000 \mathrm{~Hz}$ and the cancelling frequency $(2000 \mathrm{~Hz}$ ) is in the range of $600-3000 \mathrm{~Hz}$ where the human ear is sensitive to sound (Figure 5); however, for $\Delta \mathrm{t}=4 \mathrm{CA}$ and $5 \mathrm{CA}$, there are amplifying frequencies in the $600-3000 \mathrm{~Hz}$ range (pink column in Table 4).

This is a reason why the combustion noise at $\Delta \mathrm{t}=3 \mathrm{CA}$ (black line) is the lowest in Figure 27.

Figure 28 plots the overall combustion noise versus the indicated thermal efficiency for all the plots in Figure 26. The combustion noise was the lowest at Point B (plot with light green square) 87.1 dBA maintaining $50.3 \%$ thermal efficiency, and the combustion noise increased with the increase in the length of time in crank angle between the peaks of the rate of pressure rise in Peaks 2 and 3 $\left(d P / d \theta_{2-3}\right)$, as shown by the black dotted arrow in Figure 26.

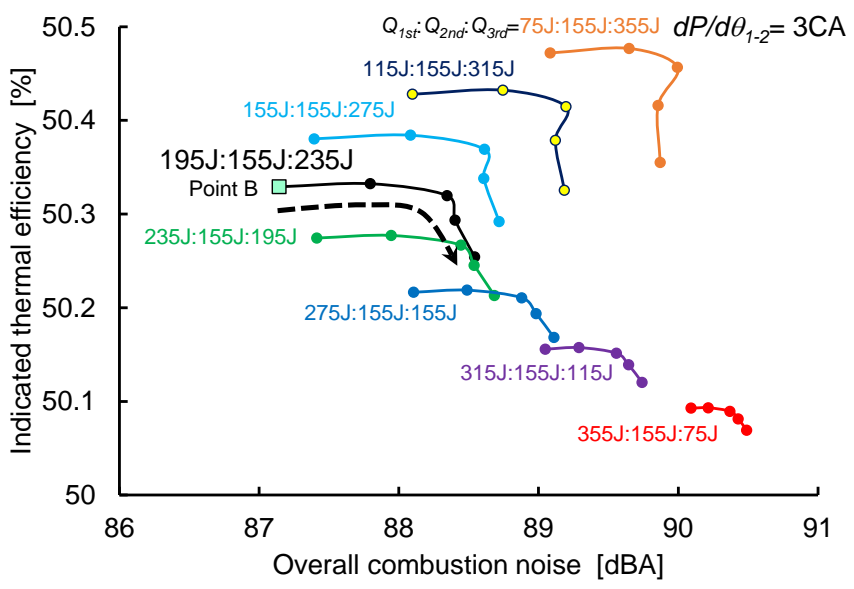

Figure 28. Overall combustion noise vs indicated thermal efficiency for the plots in Figure 26 
From these simulation results, the Point B is the optimum condition for low combustion noise maintaining a high thermal efficiency, and Figure 29 shows the histories of the rate of heat release and pressure rise at Point B.
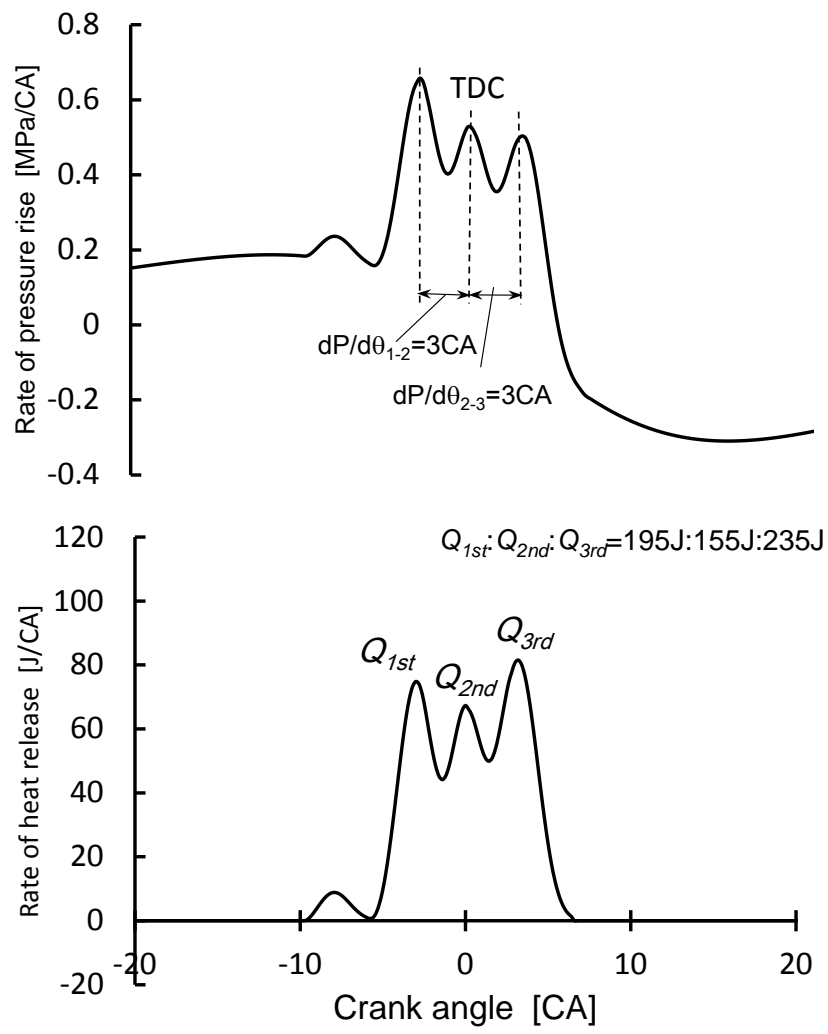

Figure 29. Histories of the rates of pressure rise and heat release at Point B in Figure 28

\section{Test 4: Evaluation of Accuracy of the Simulation Results in Test 3 by Engine Tests}

With the test engine, the first and second heat releases show premixed diesel combustion, however the third heat release may become diffusion combustion in the three stage combustion. To further elucidate this, the engine was operated with three types of two stage combustion ( $\operatorname{Twin}_{1-2}$, $\operatorname{Twin}_{2-3}$, and $\left.\operatorname{Twin}_{1-3}\right)$, as shown in Figure 15 , and the effects of the three stage combustion on the combustion noise reduction in these three cases was investigated.

The cylinder pressure level of each of the two stage combustion tests is shown in Figure 30. In the simulation Figure 24, the amplifying and reduction frequencies of $\mathrm{Twin}_{1-3}$ are around $2000 \mathrm{~Hz}$ and 1000 $\mathrm{Hz}$ respectively, and in the engine tests, the amplifying and reduction frequencies of $\mathrm{Twin}_{1-3}$ are around $2000 \mathrm{~Hz}$ and $900 \mathrm{~Hz}$ respectively. The amplifying frequency of $\mathrm{Twin}_{1-3}$ overlaps the reduction frequency of Twin ${ }_{1-2}$ and $\operatorname{Twin}_{2-3}$, and here combustion noise reduction in the three stage combustion can be expected in the engine test.

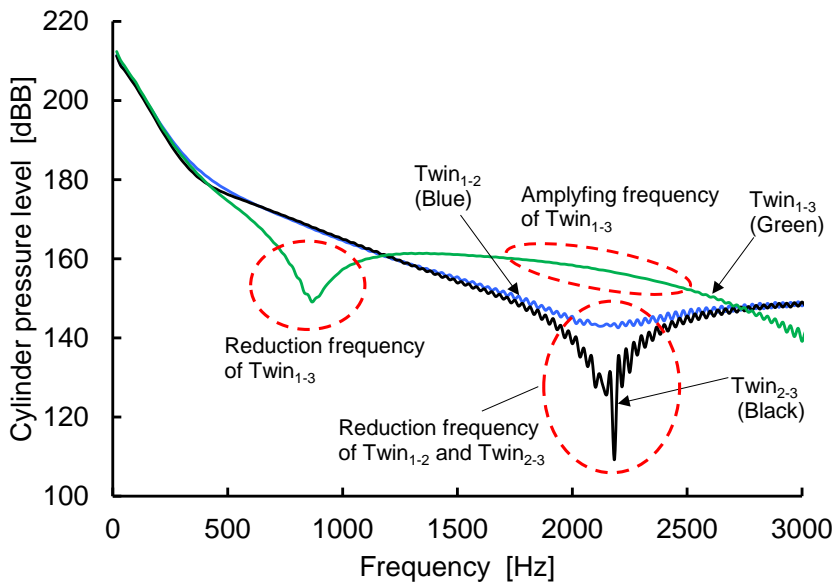

Figure 30. Cylinder pressure level of three sets of two stage heat releases, Twin $_{1-2}$, Twin $2-3$ and Twin $1-3$, (Engine test)

\section{Test 5: Effects of Multistage Combustion on the Indicated Thermal Efficiency and Combustion Noise (Simulation)}

The optimum histories of the heat release rates for low combustion noise and high thermal efficiency were calculated by simulations in single, two, and three stage combustions. Further, the three stage combustion was synthesized from the heat release histories of Twin $_{1-2}$ and Twin $_{2-3}$ of the engine test data in Figure15, termed the "synthesized three stage combustion from engine data". The heat release histories are shown in Figure 31, and the frequency characteristics of the overall combustion noise are shown in Figure 32.

The large reduction in overall combustion noise maintaining the high degree of constant volume can be achieved with increases in the number of fuel injections near the TDC, however if the number of fuel injections is higher than four, a deterioration in the degree of constant volume becomes an issue of concern, as the combustion after top dead center becomes diffusion combustion.

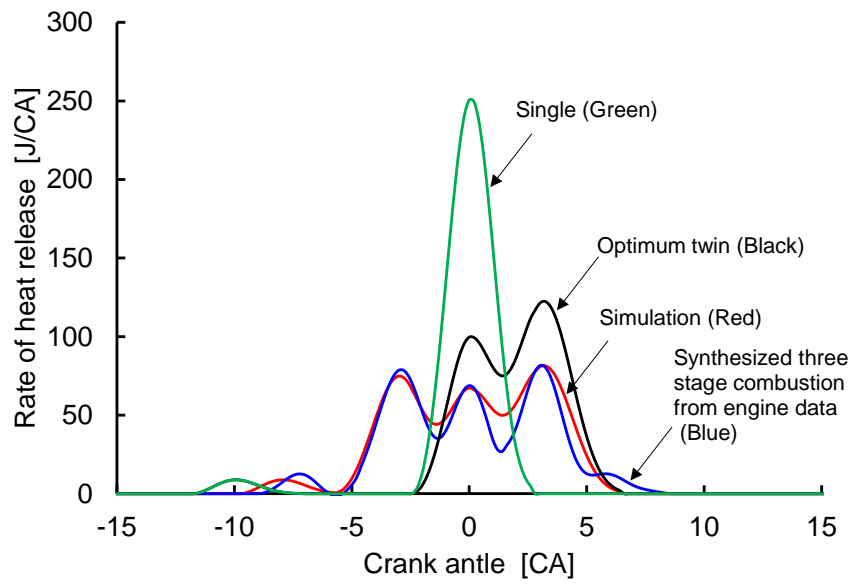

Figure 31. Optimum histories of heat release rate for single stage, two stage, and three stage combustions 


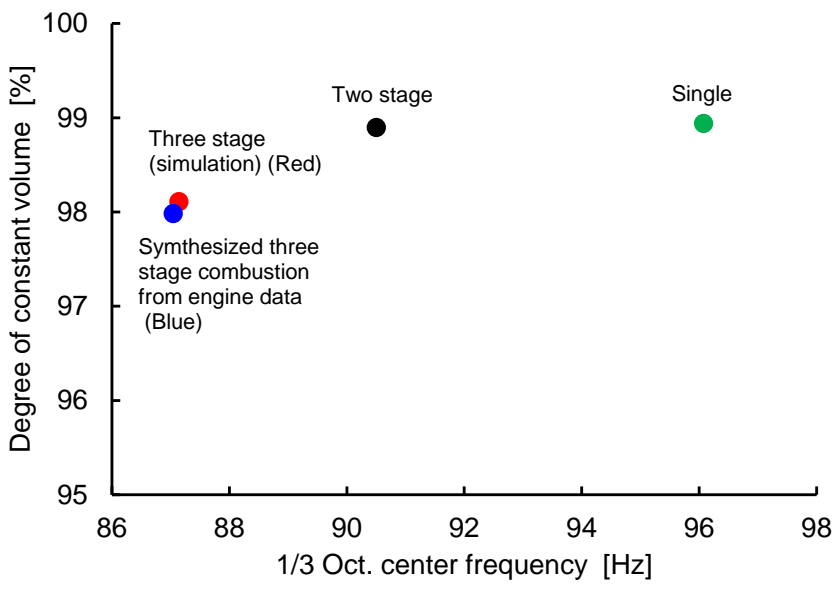

Figure 32. Plots of frequency characteristics of overall combustion noise

\section{Conclusions}

This paper investigates combustion noise reduction maintaining high thermal efficiency by multiple fuel injections with numerical simulations and engine tests. The conclusions of the investigations may be summarized as follows:

1. Multiple fuel injections near top dead center is effective for combustion noise reduction maintaining a high degree of constant volume, because of the reduction in the maximum rates of heat release in each heat release and the noise reduction effect by the noise cancelling spike (NCS) combustion. The NCS processes become increasingly complex with more fuel injections, and the amplifying and canceling frequencies can be controlled by the length of time in crank angle between the peaks of the rates of pressure rise.

2. In the late two stage combustion, the combustion noise reduction was most effectively achieved when the heating value of $Q_{2 n d}$ is higher than that of $Q_{1 s t}$, because the $Q 2_{n d}$ heat release occurs during the expansion stroke and much energy is required for $Q_{2 n d}$ to be able to reduce the combustion noise generated by the $Q_{1 s t}$ heat release. However, in the early two stage combustion, the $Q_{1 s t}$ heat release occurs during the compression stroke and the combustion noise reduction by the early two stage NCS combustion is more effective than the combustion noise reduction by the late two stage NCS combustion.

3. In the three stage combustion, the first heat release is effective in lowering the combustion noise around $1500 \mathrm{~Hz}$, and the third heat release must be the largest of the three heat releases to reduce the combustion noise by the NCS effects.

4. With the results of three stage combustion at the 0.6 MPa IMEP and $2000 \mathrm{rpm}$ condition, the optimum heat release shape for the lowest combustion noise and higher indicated thermal efficiency is shown in Figure 28. The heating values of $Q_{1 s t}, Q_{2 n d}$, and $Q_{3 r d}$ are $195 \mathrm{~J}, 155 \mathrm{~J}$, and $235 \mathrm{~J}$ respectively, and the length of time in crank angle between the peaks of the rate of $d P / d \theta_{1-2}$ and $d P / d \theta_{2-3}$ were $3 \mathrm{CA}$. The combustion noise and the indicated thermal efficiency were $87.1 \mathrm{dBA}$ and $50.3 \%$ respectively.

5. A large reduction in overall combustion noise maintaining a high degree of constant volume can be achieved with increases in the number of the fuel injections near top dead center, however with more than four fuel injection, the deterioration in the degree of constant volume becomes an issue of concern, as the combustion after top dead center becomes diffusion combustion.

\section{References}

1. Murayama, T., Kojima, N., and Satomi, Y., "A simulation of Diesel Engine Combustion Noise”, SAE Technical Paper 760552, 1976

2. Kojima, N., "An Evaluation of Combustion Noise Generation in Diesel Engine Structure”, SAE Technical Paper 890126, 1989

3. Komori, M., Miura, Y., Mikami, M., and Kojima, N., "19 Separation of Combustion Noise using Transient Noise Generation Model”, SAE Technical Paper 2001-10-29, 2002

4. Sjoberg, M., and Dec, J., "Effects of Engine Speed, Fueling, and Combustion phasing on the Thermal Stratification required to Limit HCCI Knocking Intensity”, SAE Technical Paper 200501-2125, 2006

5. Johansson, T., Johansson, B., Tunestal, P., and Aulin, H., "HCCI Operating Range in a Turbo-charged Multi Cylinder Engine with VVT and Spray Guided DI”, SAE Technical Paper 2009-01-0494, 2009

6. Scarpati, J., Wikstrom, A., Jonsson, O., Glav, R., Handel, P., and Hjalmarsson, H., "Prediction of Engine Noise using Parameterized Combustion Pressure Curves”, SAE Technical Paper 2007-01-2373, 2007

7. Shahlari, A., Hocking, C., and Ghandhi, J., "Comparison of Compression Ignition Engine Noise Metrics in LowTemperature Combustion Regimes”, SAE Technical Paper 2013-01-1659, 2013

8. Shibata, G., Shibaike, Y., Ushijima, H., and Ogawa, H., "Identification of Factors Influencing Premixed Diesel Engine Noise and Mechanizm of Noise Reduction by EGR and Supercharging”, SAE Technical Paper 2013-01-0313, 2013

9. Okubo, M., and Yonezawa, T., "Study of Method of Separate Engine Noise Sources Using Coherence Analysis”, JSAE Technical Paper 896021, vol. 40, pp152-158, 1989

10. Shibata, G., Ushijima, H., Ogawa, H., and Shibaike, Y., "Combustion Noise Analysis of Premixed Diesel Engine by Engine Tests and Silumations”, SAE Technical Paper 2014-011293, 2014

11. Shibata, G., Ishii, K., Ushijima, H., Shibaike, Y., and Ogawa, H., "Optimization of Heat Release shape and the Connecting Rod Crank Radius Ratio for Low Engine Noise and High Thermal Efficiency of Premixed Diesel Engine Combustion”, SAE Technical Paper 2015-01-0825, 2015

12. Fuyuto, T., Taki, M., Ueda, R., Hattori, Y., Kuzuyama, H., and Umehara, T., "Noise and Emissions Reduction by Seond Injection in Diesel PCCI Combustion with Split Injection”, SAE Technical Paper 2014-01-2676, 2014

13. Shibata, G., Nakayama, D., Okamoto, Y., and Ogawa, H., "Diesel Engine Combustion Noise Reduction by the Control of Timings and Heating Values in Two Stage High Temperature Heat Releases”, SAE Technical Paper 2016-01-0731, 2016

\section{Contact Information}

For further information please contact:

Gen Shibata, email: g-shibata@eng.hokudai.ac.jp

\section{Acknowledgments}

This research is one of the projects in the Strategic Innovation Promotion Program (SIP) and is financially supported by the Japan Science and Technology Agency. 


\section{Abbreviations}

\begin{tabular}{|c|c|}
\hline ATDC & After top dead center \\
\hline CA10 & Crank angle of $10 \%$ burn \\
\hline CA50 & Crank angle of $50 \%$ burn \\
\hline CA90 & Crank angle of $90 \%$ burn \\
\hline $\mathrm{CD}$ & Combustion duration (CA10-90) \\
\hline $\mathrm{CNL}$ & Combustion noise level \\
\hline $\mathrm{CPL}$ & Cylinder pressure level \\
\hline DI & Direct injection \\
\hline$d P / d \theta_{1-2}$ & $\begin{array}{l}\text { Length of time in crank angle between the peaks of } \\
\text { the rate of pressure rise in Peaks } 1 \text { and } 2\end{array}$ \\
\hline$d P / d \theta_{2-3}$ & $\begin{array}{l}\text { Length of time in crank angle between the peaks of } \\
\text { the rate of pressure rise in Peaks } 2 \text { and } 3\end{array}$ \\
\hline$d P / d \theta_{1-3}$ & $\begin{array}{l}\text { Length of time in crank angle between the peaks of } \\
\text { the rate of pressure rise in Peaks } 1 \text { and } 3\end{array}$ \\
\hline ECU & Engine control unit \\
\hline EGR & Exhaust gas recirculation \\
\hline EVO & Exhaust valve open \\
\hline FFT & Fast Fourier transformation \\
\hline $\mathrm{H}$ & Transfer characteristic \\
\hline $\mathrm{HCCl}$ & Homogeneous charge compression ignition \\
\hline HTHR & High temperature heat release \\
\hline IMEP & Indicated mean effective pressure \\
\hline IVC & Intake valve close \\
\hline LTHR & Low temperature heat release \\
\hline M & Parameter for heat release shape in Wiebe function \\
\hline MNL & Mechanical noise level \\
\hline $\mathrm{PCCl}$ & Premixed charge compression ignition \\
\hline$\theta_{z}$ & Combustion duration in Wiebe function \\
\hline$Q_{1 s t}$ & Heating value in the first HTHR \\
\hline$Q_{2 n d}$ & Heating value in the second HTHR \\
\hline$Q_{3 r d}$ & Heating value in the third HTHR \\
\hline RHR & Rate of heat release \\
\hline $\mathrm{RHR}_{\max }$ & Maximum rate of heat release \\
\hline SA & Structure attenuation \\
\hline SOI & Start of injection \\
\hline SPL & Sound pressure level \\
\hline
\end{tabular}

\section{Appendices}

\section{Appendix 1: The Basis of the Coherent Method for the Combustion Noise Calculation}

In this paper, the combustion noise was calculated by the coherent method, and the following describes the basis for the coherent method. The following is the parameters involved.

$h(t)$ : Transfer characteristics of the engine

$x(t)$ : In-cylinder pressure (input)

$y(t)$ : Engine noise (combustion noise plus other noises (mainly mechanical noise)) (output)

$u(t)$ : Other Noises, noise other than the combustion noise

The $x(t)$ and $y(t)$ are measurable parameter variables.

Figure 3 shows the combustion noise generation mode and the incylinder pressure $x(t)$ is transformed to combustion noise via $h(t)$. The engine noise $y(t)$ can be expressed as in equation a-1

$y(t)=h(t) * x(t)+u(t)$
With Fourier transformation on both sides and

$Y(k)=H(k) * X(k)+U(k)$

the transfer characteristic $H(k)$ can be defined by equation a-3.

$H(k)=W_{x y}(K) / W_{x x}(k)$

$W_{x x}$ : Power spectrum by the FFT analysis of the in-cylinder pressure waveform

$W_{x y}$ : Cross power spectrum by the FFT analysis of the sound pressure of the engine noise level and pressure waveform

The coherent combustion noise $C C N L(k)$ can be calculated from the transfer characteristic $H(k)$ and cylinder pressure level $X(k)$ as in equation a-4, and then the A weighted sound pressure level applied.

$\operatorname{CCNL}(k)=H(k) * X(k)$

$C C N L(k)$ : Coherent combustion noise

Then, the engine structure attenuation can be calculated from equation a-5.

$S A(k)=C C N L(k)-X(k)$

$S A(k)$ : Structure attenuation

In the simulation, the in-cylinder pressure history was calculated from the heat release history by the Runge-Kutta numerical method and the combustion noise $C N L(k)$ can be calculated from the structure attenuation $S A(k)$ and in-cylinder pressure level $X(k)$ by equation a-5.

$C N L(k)=S A(k)+X(k)$

$C N L(k)$ : Combustion noise level

Overall, when the structure attenuation has been obtained, the combustion noise can be calculated from the in-cylinder pressure data.

\section{Appendix 2: The Diffusion Combustion of the Third Heat Release in the Three Stage Combustion}

As shown in Figure AP-1 for the three stage combustion, the first and second heat releases in the test engine show premixed diesel combustion and the third heat release shows diffusion combustion. This is because available oxygen in the cylinder has been consumed by the first and second heat releases. To make the premixed combustion in the third heat release, the boosted pressure is increased and the fuel ratio for the three injections was varied. Figure AP-2 shows the results, here premixed combustion in the third heat release has been achieved, and the operational range of the three stage premixed diesel combustion is now under investigation. 


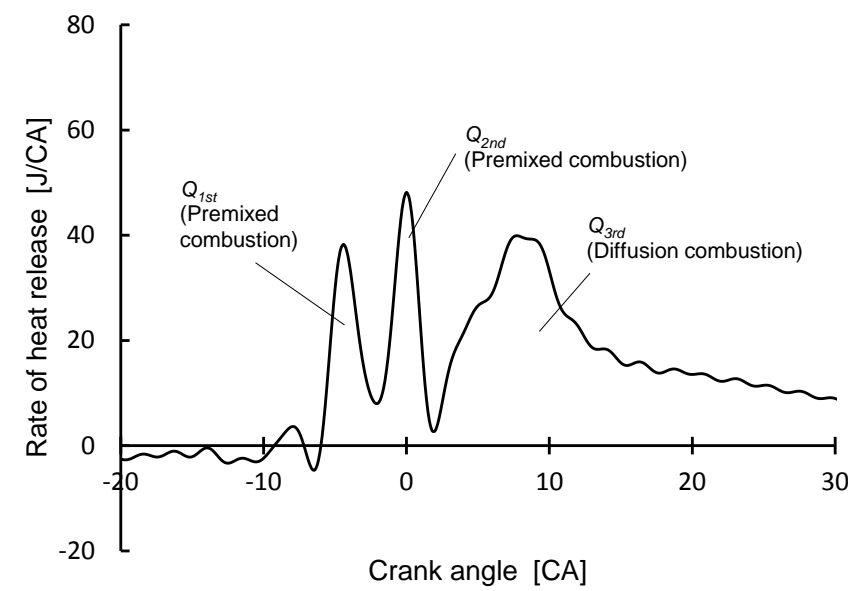

Figure AP-1. Heat release shape of three stage combustion in the case of diffusion combustion in the $Q_{3 r d}$

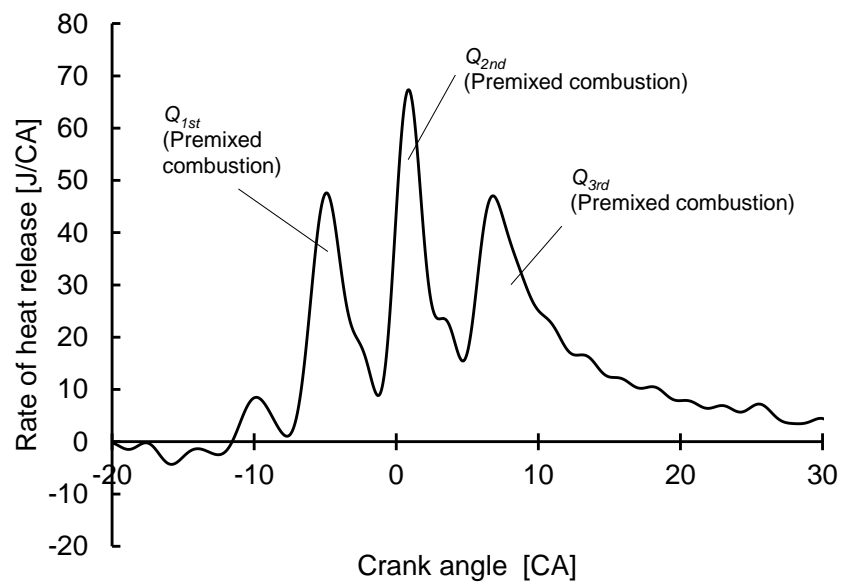

Figure AP-2. Heat release shape of three stage combustion in the case of premixed combustion in the $Q_{3 r d}$ 
Page 15 of 15 